San Jose State University

SJSU ScholarWorks

Doctoral Projects

Master's Theses and Graduate Research

$5-2019$

\title{
Identifying Perceived Barriers to Primary Health Care Access in Rural, Medically Underserved Areas
}

Suzanne Hewitt

California State University, Northern California Consortium Doctor of Nursing Practice

Follow this and additional works at: https://scholarworks.sjsu.edu/etd_doctoral

Part of the Family Practice Nursing Commons

\section{Recommended Citation}

Hewitt, Suzanne, "Identifying Perceived Barriers to Primary Health Care Access in Rural, Medically Underserved Areas" (2019). Doctoral Projects. 106.

DOI: https://doi.org/10.31979/etd.bshw-a3dh

https://scholarworks.sjsu.edu/etd_doctoral/106

This Doctoral Project is brought to you for free and open access by the Master's Theses and Graduate Research at SJSU ScholarWorks. It has been accepted for inclusion in Doctoral Projects by an authorized administrator of SJSU ScholarWorks. For more information, please contact scholarworks@sjsu.edu. 


\section{ABSTRACT \\ IDENTIFYING PERCEIVED BARRIERS TO PRIMARY CARE ACCESS \\ IN RURAL MEDICALLY UNDERSERVED AREAS}

Persons living in rural areas designated as having primary care provider shortages often lack access to timely and appropriate levels of care, frequently forcing them to forego care, delay treatment, or seek care in an emergency department for non-urgent complaints. This qualitative study reviewed evidence-based research and data generated from two focus groups sessions to generate a body of distinctive knowledge of the barriers to primary healthcare access as perceived by members of this rural, medicallyunderserved area of northern California. The theme that was identified, through conventional qualitative content analysis, as most prevalent among subjects was the inability to schedule timely appointments with their primary care provider for unexpected minor illnesses or injuries: with average reported wait times for an appointment from one to three weeks, which was unacceptable to all participants. A secondary theme, endorsed by $100 \%$ of focus group participants, was the ability of a same-day, walk-in, immediate care clinic operated by a family nurse practitioner to meet the needs of patients unable to otherwise receive safe, timely, effective, efficient, equitable, and patient-centered health care. Implications for nursing practice include, through implementation of this type of practice model, the ability to offer improved quality of health care and cost effectiveness while providing a short-term solution to an otherwise complex and multi-layered health care systems challenge.

Suzanne Hewitt

May 2019 



\title{
IDENTIFYING PERCEIVED BARRIERS TO PRIMARY HEALTH CARE ACCESS IN RURAL, MEDICALLY UNDERSERVED AREAS
}

by

Suzanne Hewitt

\author{
A project \\ submitted in partial \\ fulfillment of the requirements for the degree of \\ Doctor of Nursing Practice \\ California State University, Northern Consortium \\ Doctor of Nursing Practice
}

May 2019 
DocuSign Envelope ID: ACD5EB83-7901-4E93-97C2-40DE2AC99048

\section{APPROVED \\ For the California State University, Northern Consortium Doctor of Nursing Practice:}

We, the undersigned, certify that the project of the following student meets the required standards of scholarship, format, and style of the university and the student's graduate degree program for the awarding of the Doctor of Nursing Practice degree.

$\underline{\text { Suzanne Hewitt }}$

Project Author

Susan MCMesh

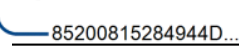

Susan McNiesh, PhD, MS, RNC-OB (Chair)

Nursing

lito fink

Lilo Fink, DNP, FNP-BC

MCDH Nursing

Lawrence Turner

Lawrence Turner, MA

MCDH Information Technology 


\section{AUTHORIZATION FOR REPRODUCTION \\ OF DOCTORAL PROJECT}

$\underline{X}$

I grant permission for the reproduction of this project in part or in its entirety without further authorization from me, on the condition that the person or agency requesting reproduction absorbs the cost and provides proper acknowledgment of authorship.

Permission to reproduce this project in part or in its entirety must be obtained from me.

Signature of project author: Suzanne Hewitt 


\section{ACKNOWLEDGMENTS}

I would first like to sincerely thank my committee for their support, encouragement and guidance throughout this process: Dr. Susan McNiesh, my committee chair, the impetus for my scholarly momentum; Dr. Lilo Fink, my mentor, dear friend, and role model; and Lawrence Turner, my information technology master and enthusiastic advocate.

The completion of this project would not have been possible without the support of my core group of fellow Doctors of Nursing Practice students at California State University: Dr. Hyacinth Carreon, Dr. Michelle Harris, Dr. Diane O'Laughlin, and Dr. Sharon Sprague. You are each paragons of excellence in nursing professionalism: I am proud that I may now call you Doctors, and will treasure your friendships forever. I would also like to thank two exceptional nurses with whom I had the privilege of working at Parkland Memorial Hospital: Dr. Kristie Brown, who encouraged me to become an advanced practice nurse, and Dr. Randy Blanchard, whose colorful words of encouragement and perseverance have helped keep me grounded and smiling whenever I felt discouraged.

This project could not have been completed without the contributions of my focus group members: I want to respectfully acknowledge each of them for their contributions, and for caring enough about the health of our community to share their insights with me.

Finally, to my beautiful family: my husband Henry, love of my life, who has always encouraged me, believed in me, and been proud of me; my son Marlon and his wife Julia, who make me proud every day; and my granddaughter Gwyneth Mae (Gwen), who makes it all worthwhile. 


\section{TABLE OF CONTENTS}

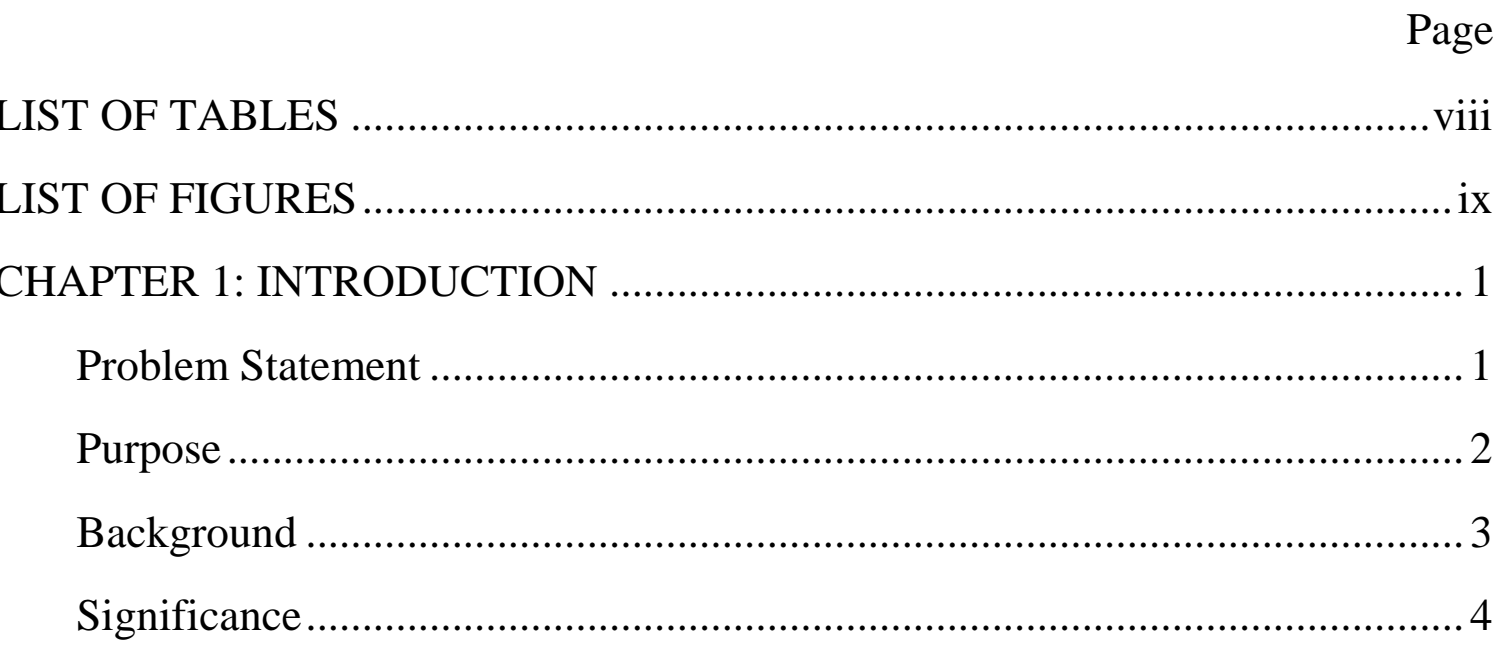

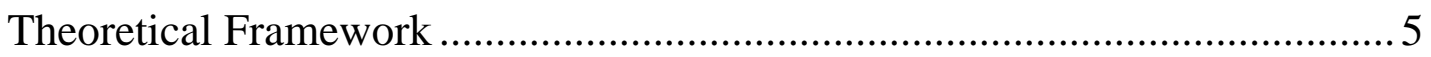

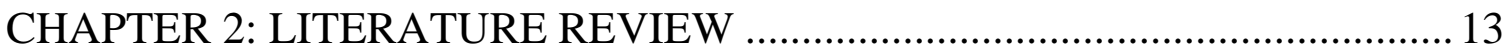

Barriers to Care and Health Care Utilization Among the Publicly Insured.... 13

Primary Care Access Barriers as Reported by Nonurgent Emergency Department Users: Implications for the US Primary Care Infrastructure

Access to Primary and Specialty Care and Emergency Department Utilization of Medicaid Enrollees Needing Specialty Care.................. 15

Why Aren't More Primary Care Residents Going into Primary Care? ........... 16

Self-Perceptions of Aging and Perceived Barriers to Care: Reasons for Health Care Delay …………………………………………..................... 18

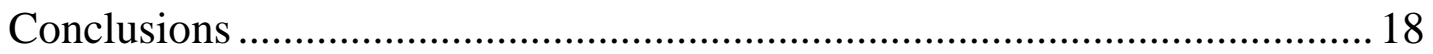

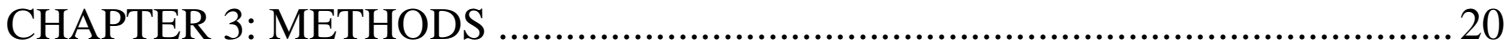

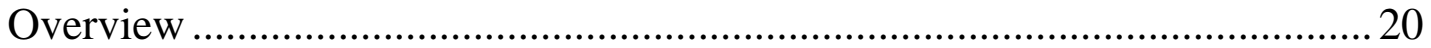

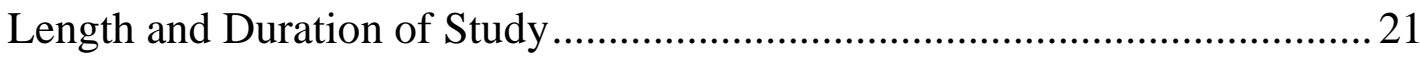

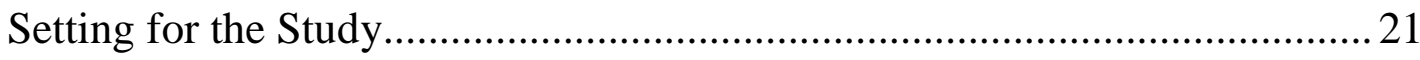

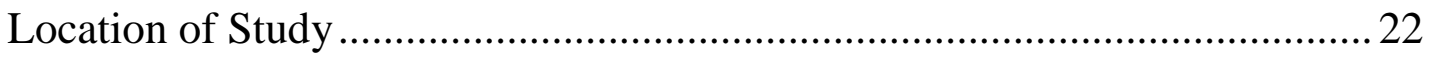

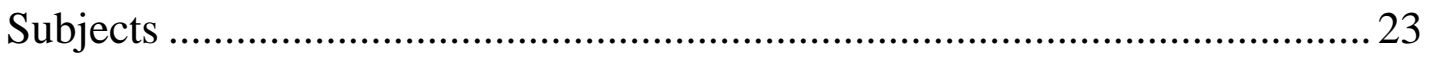




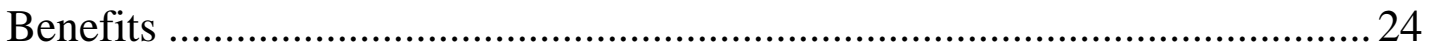

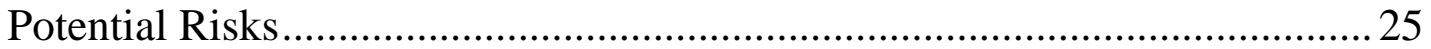

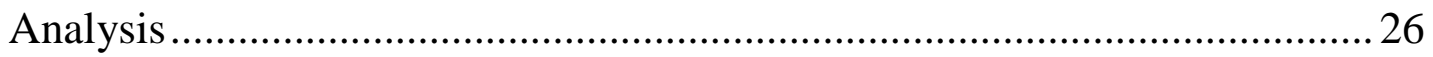

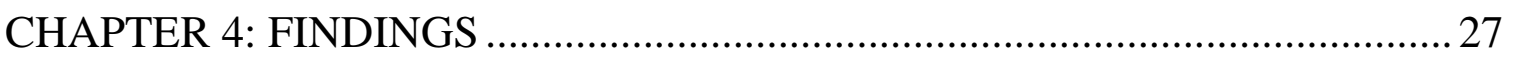

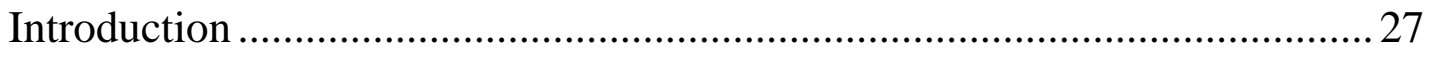

Demographics of Focus Group Participants ........................................... 28

Theme 1: People Living in Rural Areas have Unique Health Care Needs ..... 28

Theme 2: Community Members Perceive Significant Barriers to Primary Care Access.

Theme 3: Immediate Care is Meeting the Needs of Community Members Requiring Care for Unexpected or Episodic Illness or Injury ............ 39

Summary of Findings .................................................................. 40

CHAPTER 5: DISCUSSION ................................................................ 42

Comparison of Urban and Rural Health Care Demographics ..................... 43

Project Outcomes ............................................................................ 46

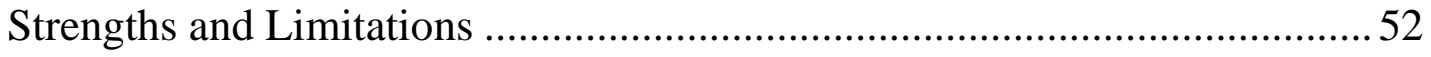

Nursing Implications ................................................................ 53

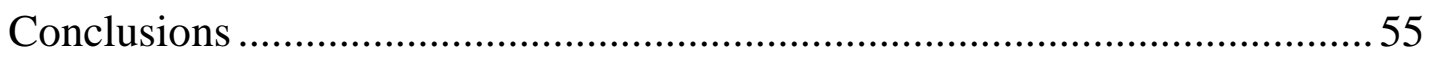

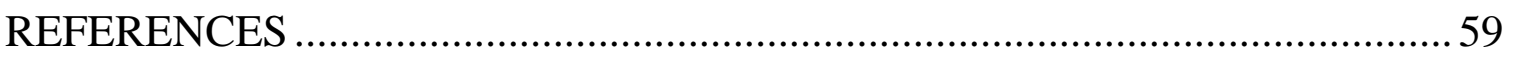

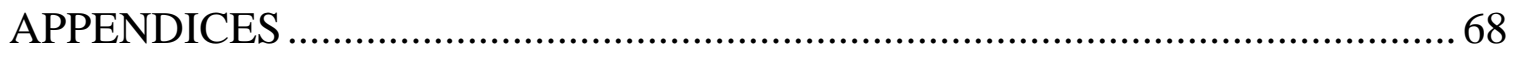

APPENDIX A: CONSENT FORM ....................................................... 70

APPENDIX B: FOCUS GROUP GUIDELINES ..................................... 72 


\section{LIST OF TABLES}

Page

Table 1. Differences in Rural and Urban Health Care Indicators .......................... 44

Table 2. Comparison of County, State, and U.S. Demographics ........................... 46 


\section{LIST OF FIGURES}

Page

Figure 1. Patients Seen in Immediate Care by Insurance Type. ...........................50

Figure 2. Patients Seen in Immediate Care by Primary Care Provider .................. 51 


\section{CHAPTER 1: INTRODUCTION}

\section{Problem Statement}

Persons living in rural, medically underserved areas (MUAs) throughout the United States experience more barriers to accessing healthcare than their urban counterparts (Rural Health Information Hub, 2019). Nationally, 20\% of the population lives in rural areas but only $10 \%$ of physicians practice in rural areas (Hospital \& Health Networks, 2016). In California, 75\% of the state is designated as a primary care shortage area and more than $50 \%$ of the state is designated as a primary care health professional shortage area or medically underserved area/population (Office of Statewide Health Planning and Development [OSHPD], 2015). Designation as a MUA or medically underserved population (MUP) is granted by the Health Resources \& Services Administration (HRSA), a division of the U.S. Department of Health and Human Services (DHHS), and is based on a score determined by four factors: the percentage of the population over the age of 65 , the percentage of population living below the federal poverty level, infant mortality rates, and the population-to-provider ratio. Mendocino County, in northern California, has been designated as medically underserved area/population and while the provider-to-population ratios for physicians and non-physician providers are slightly above those of the rest of California and the U.S., over 19\% of residents are living below the poverty level and nearly $22 \%$ of the population 
are over the age of 65 , compared to $14 \%$ for the state of California (Healthy Mendocino, 2018).

Rural residents have been found to have higher rates of chronic illness and disability when compared to urban dwellers due in part to inadequate health care resources, increased risk factors, and a decreased likelihood of practicing healthpromoting behaviors such as preventative screening exams and immunizations (Leight, 2003). Inappropriate solutions to inadequate health care resources care are a delaying of care, foregoing care, or seeking care in an emergency department (ED) for non-emergent complaints (Allen, Call, Beebe, McAlpine, \& Johnson, 2017).

\section{Purpose}

This project was a qualitative study designed to increase understanding of the factors that, according to patients' perceptions, combine to limit or prevent access to primary care in medically underserved rural populations (MUPs) in coastal Mendocino County. The purpose of the study was to add to existing knowledge by identifying these perceptions through patient focus groups, and to propose practical solutions to these perceptions. The data generated will form the basis for a model of care that can be presented to health care professionals and administrators with the purpose of facilitating access to primary healthcare in this and other similar, rural communities over a relatively short period of time with 
minimal outlay of capital and with a minimum of disruption to processes already in place.

\section{Background}

Vulnerable populations, including persons living in designated primary care shortage areas, often lack access to safe, effective, timely, equitable, and patientcentered care (Mareno, 2016). Barriers to accessing appropriate and timely primary care are multifactorial. As more patients have become insured under the Affordable Care Act (ACA), providers and health professionals are being required to see more patients with less time allotted for the encounter (U.S. Health Policy Gateway, 2014). Factors which contribute to the shortage of healthcare providers include a) the retirement of practicing providers, b) inability or unwillingness to accept new patients by aging providers seeking to reduce their workload, c) difficulty in recruiting and retaining new providers to rural areas, and d) the fact that fewer medical students are pursuing family practice careers, leaving a smaller pool of physicians to serve in rural areas (Ewing \& Hinkley, 2013).

The lack of access to primary care can force patients to seek inappropriate solutions to illness and/or minor injuries including the delay of time to care, receiving no care, or seeking care in an emergency department (ED) for nonemergent complaints (Allen, et al., 2017).. Additionally, these community members often forego routine screening for preventable or treatable conditions. Leight (2003) applied the Vulnerable Populations Conceptual Model (VPCM) to 
rural health and noted that patients who are unable to access necessary health care are vulnerable to higher morbidity rates because of delayed diagnoses and increased illness (Leight, 2003).

The research question that this qualitative study proposed to answer was "How do patients living in rural, medically underserved areas perceive their ability to access primary care services within their community? " Data was generated from information obtained from two focus groups sessions with patients living in coastal Mendocino County. The sessions were moderated, and explored the perceptions of participants with regard to their ability to access primary care healthcare services.

\section{Significance}

The Institute of Medicine published a framework for assessment of quality in health care in 2001, which lists six domains for quality measurement. The six domains of health care quality are known by the acronym STEEEP: safe, timely, effective, efficient, equitable, and patient-centered (Agency for Healthcare Research and Quality [AHRQ], 2016). Persons in rural, medically underserved areas are frequently unable to access health care in a timely or efficient manner, and may be utilizing the ED inappropriately, which is not equitable, or foregoing care, which is not safe or effective.

Healthy People 2020 identifies Access to Health Care as one of its leading health indicators noting that a quarter of Americans do not have a PCP or medical 
home for primary care services. A second leading health indicator identified by Healthy People 2020 is Clinical Preventive Services. For adults, these services include screening for the prevention or early detection and treatment of colorectal cancer, breast cancer, and cervical cancer. For many persons in medically underserved areas, impaired access to primary care services means that they are not receiving medical screening for these cancers nor are they having weight, blood pressure, cholesterol and blood sugars monitored putting them at risk for having undiagnosed diabetes and cardiac disease (Singh, Scott, Krueger, \& Bush, 2018).

\section{Theoretical Framework}

The theoretical framework for the study, the vulnerable populations conceptual model (VPCM), is easily adapted to rural populations and describes the relationship between resource availability, relative risk, and health status in vulnerable populations. This model is used as a theoretical framework at the University of California Los Angeles School Of Nursing's Center for Vulnerable Populations Research (Nyamathi, Koniak-Griffin, \& Greengold, 2007) and is a reasonable model for describing a vulnerable population and laying the groundwork for the development of programs and practices to increase access to healthcare. The VPCM was first presented by two doctorally prepared nurses, Jacqueline Flaskerud and Betty Winslow, in 1997. 
As noted by Rawlett (2011), the fundamental assumption of the VPCM is that there is a non-linear and interactive relationship between the three concepts of the model: resource availability, relative risk, and health status. Strengths and/or weaknesses in any of the three concepts will have an effect on the remaining concepts. People living in rural, medically underserved areas are vulnerable populations and have limited resource availability and, as a result of these limited resources, higher relative risk for morbidity and premature mortality (Nyamathi et al., 2007).

\section{Concepts}

A conceptual-theoretical-empirical (C-T-E) structure similar to one developed by Leight (2003) can be used to demonstrate the concepts, theoretical structure and empirical indicators for the VPMC and their relationships to one another within the realm of to rural populations. The first of the three concepts described by the VPMC is resource availability. The resources specific to this concept are social resources and environmental resources. Social resources are further broken down into human capital with the empirical indicators of income, jobs, education and housing, social connectedness to family and community, and social skills. Healthcare is seen as an environmental resource with availability of resources and access to services the major barriers (Leight, 2003).

Relative risk, the second concept described in the VPCM, refers to exposure to risk factors. Flaskerud and Winslow (1998) cited the risk factors most 
commonly studied and reported as quality of healthcare, lifestyle, behaviors, exposure to stressful events, and choices as well as the use of health promotion services like immunization programs and screening programs for cervical, breast and colon cancer. Behaviors of adults and associated exposure to risk are reported by the CDC and include diet and exercise practices, use of tobacco, substance use, drinking and driving, and automobile restraint use. Additional data for behaviors more commonly found in adolescents: sexual behaviors, unplanned pregnancy, abortion, sexually transmitted diseases, and risk-taking behaviors which contribute to injuries; is also reported (Flaskerud \& Winslow, 1998). For children, data pertaining to prenatal exposure to addictive drugs, growth and development, immunizations, infectious diseases, exposure to lead, and firearm-related injuries is collected (Flaskerud \& Winslow, 1998).

The third concept in the VPCM is health status, or morbidity and mortality. The VPCM posits that morbidity and mortality in the community, or health status, is directly influenced, positively or negatively, by access to healthcare, or resource availability, which in turn affects relative risk and, ultimately, health status (Rawlett, 2011).

\section{Relationships}

The first relationship is between resource availability and relative risk, and suggests that limitations in resource availability increase the relative risk, or vulnerability to poor health. Resource availability includes social resources such 
as income, jobs, education, and housing (human capital), social connectedness, social skills or status, and environmental resources, which in this context, means access to health care (Flaskerud \& Winslow, 1998). Relative risk pertains to exposure to risk factors including inadequate health care resources, suboptimal lifestyle behaviors and choices, less engagement of health-promoting behaviors, and exposure to stressful events such as abuse, and family violence (Leight, 2003)

The second relationship is between relative risk and health status. Resident living in rural areas are less likely to engage in health-promoting behaviors (health screening, immunizations), use seat belts, or have regular physical and dental examinations. Coupled with other lifestyle behaviors and choices, these practices lead to poorer health status as evidenced by higher morbidity and mortality rates (Leight, 2003).

The final relationship is a feedback association between health status and resource availability. The explanation for this relationship is that poor health status in a community depletes socioeconomic and environmental resources (Flaskerud, J. \& Winslow, \& B., 1998). In an area already impacted by an inadequate pool of health care providers for the population, consumption of the majority of resources by a minority of community members further limits resource availability.

\section{Research, Literature, and Testing of the VPCM}

In 1975, the National Institutes of Health (NIH) sponsored a program to support pre-doctoral and post-doctoral research training in the health sciences. 
This program, known as the National Research Service Award (NRSA) training program, provides grants to both institutions and individuals (Dixon et al., 2007). The National Institute of Nursing Research (NINR) became involved and provided funding for numerous research projects with a goal of developing nurse scientists. The mission statement for the NINR specifically mentions health disparities and emphasizes the need for research in this area. The UCLA School of Nursing received its first grant from the NINR and applied it toward vulnerable populations research using the VPCM as its framework (Dixon et al., 2007).

More recently, support from the National Institutes of Health, Healthy People 2010, the Institute of Medicine, and other organizations have promoted nursing research in vulnerable populations. A 2007 article (Nyamathi et al.) in the Annual Review of Nursing Research cites the VPCM as the framework for several studies including a 2004 study of social environments and health disparities.

\section{Applicability of the VPCM to Rural Healthcare}

The VPCM is a reasonable model for describing a vulnerable population and laying the groundwork for the development of programs and practices to increase access to healthcare. A comprehensive 2003 literature review found support for the application of the VPCM to rural populations (Leight, 2003). The author noted that there has been limited nursing research or dissemination of information through scholarly writings but that the VPCM "shows promise for future research, practice and health policy initiatives" and that continued 
development of research and practice will strengthen the framework of the model (Leight, 2003, p. 447).

An advantage to the VPCM is that each concept within the model, and each empirical indicator within the concept, lends itself to further investigation and research. For example, hurdles to healthcare access which are specific to rural populations include distance to the nearest healthcare facility or specialty service, hazardous roads, hazardous weather, and lack of public transportation (Leight, 2003). A descriptive study of this barrier to healthcare access, written in a scholarly manner and with statistically significant evidence, could be presented to stakeholders as a catalyst to improve healthcare outcomes within the community. Improved outcomes could be as simple as starting a rideshare program within the community to help people get to medical appointments, or as complex as implementing a telemedicine program for local clinics or hospitals.

\section{Relevance of the VPCM in the Study of Access to Healthcare in Rural Areas}

The relevance of the VPCM in the study of barriers to healthcare access in rural, medically-underserved areas is evidenced by the logical translation of not only each concept of the model, but each empirical indicator of the model, to rural healthcare. The VPCM was selected to describe this topic not only because of its appropriateness to the topic, but also because there is very little peer-reviewed literature using this framework as a basis, and because of the likelihood of 
additional interventional projects being developed once the initial descriptive study has been completed.

Two additional models have been used in the study of vulnerable populations and may be easily adapted to the rural population: the comprehensive health seeking and coping paradigm (CHSCP) presented by Nyamathi in 1989 and the behavioral model for vulnerable populations (BMVP) developed by Gelberg, Andersen, and Leake in 2000. In the CHSCP, like the VPCM, interactive relationships are explored but the indicators used in the CHSCP pertain to the vulnerable person's environmental, personal, behavioral, sociodemographic, and health outcome spheres (Nyamathi et al., 2007). The BMVP addresses the use of health services and health outcomes at both the individual and community levels and identifies satisfaction with care as an important outcome (Nyamathi et al., 2007).

The Purnell model for cultural competence was considered for the basis of the project but was rejected, along with the health beliefs model and the theory of reasoned action, because although they adapt easily to vulnerable populations, they were not thought to be specific enough to rural populations. Flaskerud noted in 1999 that "research has shown that lack of resources, rather than the presence of risk factors, is the best predictor of illness and premature death in vulnerable populations" (Nyamathi et al., 2007, p. 6). This lack of resources, and the barriers 
to healthcare in rural, medically underserved populations, is the indicator which is the basis of this DNP project.

\begin{abstract}
Aims of Research
The research question that this study proposed to answer was "How do patients living in rural, medically underserved areas perceive their ability to access primary care services within their community?" with the hypothesis being "Patients living in rural, medically underserved areas do not have adequate access to primary care services". The study sought to generate data on how patients saw the ability to access primary healthcare, what they perceived as barriers to their ability to access healthcare, and what they perceive as possible solutions to these barriers.

Within the focus group sessions, open-ended questions such as "What would you do if you had a minor medical complaint such as ear pain, the flu, a rash, or painful urination?" and "How would you describe your attempts to establish care with a regular primary care provide in this area?" were asked. The data generated by these focus group interviews has the potential for significant implications in nursing practice and future nursing research on a larger scale as discussed in the following section on potential benefits.
\end{abstract}




\section{CHAPTER 2: LITERATURE REVIEW}

\section{Barriers to Care and Health Care Utilization Among the Publicly Insured}

A 2017 quantitative study by Allen, Call, Beebe, McAlpine, and Johnson, with a sample size of 2,194 , looked at barriers to health care among adults with Medicaid insurance in the state of Minnesota. A mail survey with telephonic follow up was utilized and multivariate logistic regression $F$ tests were used to analyze the data. The three outcomes were identified: delayed care, foregone care, and no preventative care in the past year as a result of barriers to accessing health care in this population. Patient-related, provider-related, and system-related barriers were identified and the results presented in a chart, which showed the outcomes relative to the socioeconomic demographics of the participants (Allen, et al., 2017). Patient-related factors included family or work issues and unavailability of childcare. Provider-related factors included perceived discrimination based on sex, race, ethnicity, nationality, ability to pay, or enrollment in a public health care program. Providers who did not speak the language, understand the culture or understand the religious beliefs of the patient were seen as barriers at this level, as were providers who were not perceived as trustworthy or having a welcoming office. Coverage barriers, financial barriers, and access barriers were all identified as system-level factors: lack of knowledge about services covered by the health plan, worrying about the cost of services or medications, inability to get an 
appointment, inconvenient office hours, problems with transportation, and inability to see the provider of choice. A notable strength of the study is the large sample size and that barriers at several levels (patient, provider, and system) were examined. A significant weakness of the study was that it was did not address rural populations (Allen et al., 2017).

\section{Primary Care Access Barriers as Reported by Nonurgent Emergency Department Users: Implications for the US Primary Care Infrastructure}

A 2015 mixed-methodology study by Hefner, Wexler, and McAlearney used questionnaires administered to a non-random convenience sample of 859 patients who had sought care for nonurgent complaints at one of two urban emergency department (ED)'s in Ohio was conducted over a 10-month period. The theoretical framework for the study was the Aday and Andersen framework for the study of access. There was a $65 \%$ response rate overall with $41 \%$ of respondents answering all questions making a sample size of 349 . The respondents were 18 years of age or older with $48 \%$ of patients identifying as white and $45 \%$ identifying as African America. Thirty-seven percent of the patients were covered by Medicaid and/or Medicare, $31 \%$ by private insurance, and $25 \%$ reported having no insurance. The survey consisted of seven sociodemographic questions (with four to five choices per question) and one open-ended question that asked the patient if he or she perceived any barriers to receiving health care in a primary care office. Descriptive statistics were used to answer the sociodemographic 
questions and qualitative coding was used to separate the responses into one of 3 categories and 12 subcategories, including a "no barriers" perceived category. A multiple regression tool was used to identify which sociodemographic group encountered which type of perceived barrier to primary care access.

The conclusions were that uninsured patients cited income and transportation as the greatest barriers while insured patients reported primary care infrastructure barriers such as waiting times and difficulty being seen during business hours due to employment. Strengths of the study include that the sample size was adequate, the study was well-organized and could be replicated in other settings and the findings could be used to develop solutions to inappropriate utilization of the ED. Weaknesses were the solely urban setting and the use of convenience sampling. An unexpected finding of the study was that $25 \%$ of insured respondents felt that they had no barriers to receiving health care in a primary care office, although they were still utilizing the ED for nonurgent complaints.

\section{Access to Primary and Specialty Care and Emergency Department Utilization of Medicaid Enrollees Needing Specialty Care}

Data from the Medical Expenditure Panel Survey (MEPS), sponsored by the Agency for Healthcare Research and Quality (AHRQ), along with the National Center for Health Statistics was used in Mortensen's 2014 quantitative study of 2,733 Medicaid enrollees that analyzed the relationship between access to 
providers and emergency department (ED) utilization. Descriptive statistics were used to describe the demographic and socioeconomic characteristics, how health care was being utilized, and whether access to primary care or specialty care was a problem. Multivariate analysis was used to test for heterogeneity, then logistic regression employed to estimate outcomes related to ED visits. The data showed a correlation between perceived ability to access primary care and the number of ED visits by enrollees. The study found that age, sex, race or ethnicity, marital status, education and employment status were not predictive of ED utilization but that poor health status, chronic conditions, and the presence of disability were associated with more frequent ED visits. A strength of the study was the implications for Medicaid policy based on increased utilization of the ED which has been exacerbated by the expansion of Medicaid eligibility under the Affordable Care Act. A notable weakness of the study was the lack of data on average distance to an ED, which may be a factor in the decision to utilize ED services. The study reinforced the findings that Medicaid enrollees who are unable to readily access primary care will seek care in the ED.

\section{Why Aren't More Primary Care Residents Going into Primary Care?}

This 2016 qualitative study, by Long, Chaiyachati, Bosu, Sirdar, Richards, Garg, McGarry, Solomon, Berman, Curry, Moriarty, and Huot, based on a grounded theory framework, sought to understand why more primary care residents were not pursuing careers in primary care. A homogenous sample of 24 
primary care internal medicine residents was taken: the students were interviewed for 45 minutes each with the semi-structured interviews being videotaped. The responses were then coded by an interdisciplinary team with the code structure based on grounded theory and using inductive reasoning to make generalizations based on the specific input from each respondent. The conclusion was that primary care training programs may actually discourage residents from pursuing careers in primary care as interactions with practicing physicians exposed concerns that residents had not considered upon entering residency. Foremost among the deterrents to primary care practice were the challenges of this type of practice: life stress, lack of resources to address the psychosocial needs of patients, frustration with lack of mental health resources, and fear of burn-out. A study strength was that three separate study sites were used which allowed for a richer, more varied range of experiences by the residents. Further studies using family practice residents should also be conducted. The main limitation was the size of the sample, which was too large for a grounded theory framework. Other weaknesses included the fact that the residents interviewed in this study were in primary care internal medicine programs, family medicine residents were not included in the study, and all residents were training in academic medical centers rather than community hospitals. 


\section{Self-Perceptions of Aging and Perceived Barriers to Care: Reasons for Health Care Delay}

Self-perceptions of aging and perceived barriers to care were explored in this 2017 quantitative study by Sun and Smith using data collected from the Health and Retirement Study (HRS) from mail surveys from two independent subsamples of 2,866 and 2,474 participants. The theoretical framework for this study was Anderson's behavioral model of health services use. Study variables were socioeconomic demographics plus an eight-item tool, based on the Philadelphia Morale Scale, which listed nine statements linked to reasons for delay in care. The responses were evaluated on a 6-point scale with Cronbach's alpha 0.82 for one subsample and 0.81 for the other. The results of the study showed that patients with more negative self-perceptions of aging were more likely to delay care. Many of the patients erroneously attributed symptoms indicative of acute illness to the natural aging process. Others cited scheduling or transportation issues, dislike of going to the doctor, being too busy to go to the doctor, or being fearful of certain diagnoses. This study used descriptive statistics, multinomial logistic regression, and negative binomial studies. The strengths of the study are the sample size and the patient-level barriers that have not been addressed in other studies. A weakness is the fact that self-reporting provides purely subjective data.

\section{Conclusions}

Of the five studies critiqued, the Mortensen study and the Sun and Smith studies were the two that yielded the best information relative to this study's area 
of interest. While these were both quantitative studies with large sample sizes that employed self-reporting by respondents, and relied exclusively on subjective data, perceptions were important to consider because barriers to health care access can be perceived, or subjective, as well as actual, or objective. Perceptions are better measured using a qualitative method with smaller sample sizes.

Some of the findings from studies reviewed in the literature could be applicable to the rural population, but there are distinctive differences that need to be researched for a clearer understanding of the barriers to care as perceived by this population. Certain facets of the studies reviewed can be replicated and adapted to the small, rural geographical area at the center of this study that is typical of many other northern California communities in terms of demographics, lifestyle, and political leanings. The problem of impaired access may be related to the problem of dwindling numbers of primary care providers. The outcomes of this study, along with implications for the future in terms of policy and practice recommendations, can benefit similar communities across California and the country. 


\section{CHAPTER 3: METHODS}

\section{Overview}

This evidence-based qualitative research study used data generated through focus group sessions to identify problems with current processes for procuring care in the event of unexpected illness or injury. Open-ended questions were used to guide the conversation so that information and perceptions of current practices and additional needs could be elicited. Twenty-four subjects were invited, by email, to participate in focus groups at a later date following a visit to the Immediate Care Clinic at North Coast Family Health Center. Purposive, or purposeful, sampling was utilized to identify those patients who live in the community (as opposed to tourists) and had used the walk-in clinic for minor medical complaints or injuries that are within the common realm of primary care. Examples of chief complaints included respiratory infections, influenza, ear infections, urinary tract infections, abscess and cellulitis, sprains and strains, and minor wounds.

This was a minimal risk study and no investigational or experimental procedures involving subjects were done. No special procedures of any type, including those involving electrical equipment, radioisotopes or diagnostic imaging were performed. Focus group sessions were conducted in a private meeting room at the local library and were conducted after the library was closed to the public for the day. The study was approved by the California State 
University (CSU) Fresno School of Nursing Institution Review Board. Permission to conduct the study was granted in a letter of approval from the participating institution, which has no institutional review board, ceding IRB review to CSU.

The focus group sessions followed a written guideline so that content of the sessions would flow in a similar pattern. The sessions began with a statement of the purpose and goals of the focus group sessions and a brief overview of the project goals, followed by an overview of confidentiality expectations, consent form signatures, and assignment of identifying numbers to members. A number of open-ended questions were asked to move the conversation in a direction that was designed to promote meaningful dialogue. The opening question asked the participant what he or she would do if he or she had a minor medical complaint or injury. From there, the conversation was steered toward ease of making appointments, frequency of routine healthcare screening, delayed or foregone care, the need for specialty consults, use of the emergency department for nonurgent care, personal barriers to access, barriers related to individual providers or clinics, and systems barriers.

\section{Length and Duration of Study}

The research project was conducted over the Fall 2018 and Spring 2019 semesters.

\section{Setting for the Study}

All of Mendocino County, in northern California, has been designated a medically underserved population (MUP) by the California Office of Statewide 
Health Planning and Development (OSHPD). The county covers 3,878 square miles (Zip-codes.com, 2017) with a reported 159 providers for a population of 87,497 or a provider-to-population ratio of $1: 550$. There are three hospitals in the county: Howard Memorial Hospital in Willits, Mendocino Coast District Hospital $(\mathrm{MCDH})$ in Fort Bragg, and Ukiah Valley Medical Center in Ukiah (Medicare.gov. (2019).

$\mathrm{MCDH}$ is a 25-bed rural district hospital with critical access status. The specific area of coastal Mendocino County where this study was conducted was in within the primary service area for $\mathrm{MCDH}$. This area includes seven zip codes and has a population of 19,994 (Mendocino Coast District Hospital, 2017). The area is served by 24 physician and non-physician primary care providers (PCPs), 19 of whom accept Medi-Cal (Partnership Health Plan of California, 2019), making the ratio of providers to population 1:833. A secondary service area adds another three zip codes and an additional 3,855 residents (Mendocino Coast District Hospital, 2017).

\section{Location of Study}

The research was conducted with patients living in rural, coastal Mendocino county within the primary service are of Mendocino Coast District Hospital. Focus group sessions were held at the Mendocino Public Library, a geographically central location for participants, which allowed use of a private meeting room with a separate entrance. The library was also chosen because it was 
not affiliated with the health care organization or any other group that could be construed as having an interest in the study findings.

\section{Subjects}

Two focus groups consisting of three and five participants in each group were conducted with patients identified as having used the Immediate Care Clinic at the North Coast Family Health Center for episodic or unplanned medical illness or injury. This walk-in clinic is located within a suite of primary care provider offices that are owned by, and located on the campus of, one of the two critical access hospitals (CAHs) in Mendocino County. Purposeful sampling was used to select a pool of potential participants because this type of sampling is thought to yield the most pertinent data from limited resources (Palinkas, Horwitz, Green, Wisdom, Duan, \& Hoagwood, 2015. Purposeful or purposive sampling, which suggests the inclusion of outliers (because outliers embrace the diversity within a sample population), can also yield better data in qualitative research (Barbour, 2001).

Inclusion criteria were: patients must be 18 years of age or older, and the patient needed to have been seen in the walk-in clinic during the previous six months. Exclusion criteria was any member of a protected population, any current or past patients of Dr. Lilo Fink (project committee member and focus group assistant), or any person with an expressive language disability which would 
preclude audiotaping of the participant's dialogue or any inability to give signed, voluntary consent to participate in the study and to be audiotaped.

Potential problems involving the subject group included confidentiality issues within the group: they may have shared personal health information with the moderator and her assistant, as well as others in the community. They may also have feared a loss of access to services as a result of their participation. Both of these subjects were addressed in the consent form (see Appendix A) and were discussed in the introductory portion of the focus group, with the participant given the option of opting out at any time during the session. Participants were identified by an assigned number and at no time referred to by name.

\section{Benefits}

While there were no direct benefits awarded to the participants, other than a $\$ 10.00$ gift card as a token of appreciation for participation, researchers deemed it likely that the participants in the focus groups would benefit from participation in this study by the discussion of possible solutions to their perceived barriers to healthcare access. Plans for subsequent projects include another qualitative study aimed at boosting the recruitment and retention of providers to this rural area by identifying what current local providers see as the most significant deterrent to practicing in coastal Mendocino County and other rural areas. Findings of the study related to access and screening may lead to public education presented at the various community health fairs. Because the rural community at the center of this 
study is typical of rural, medically underserved areas across the country, the findings should be of interest to other communities seeking to identify and address barriers to healthcare access in their own geographical areas.

\section{Risks}

Risks associated with the subject's participation in the study were those inherent in any focus group session: There is always the possibility that a participant will know, or know of, a fellow group member. Participants were advised that if they felt the least bit uncomfortable, the participant could join another group at another time or withdraw from the study. An agreement was made, verbally and in the consent form, that group members would not share information with outsiders or talk between each other. Any opinions given or suggestions made during the group sessions that were used in the final project remained anonymous and personal information was not published. Otherwise, there were no foreseen potential risks in the areas of psychological, social, physical, economic, or legal risk. The primary investigator did not foresee any violations of normal expectations: as the moderator she was present for both focus group sessions and her mentor, Dr. Lilo Fink, was present as the assistant and audio technician. Business cards for a licensed clinical social worker who practices locally and is familiar with the study were made available for all participants in the event that the sessions created any stress for them. 
To further protect focus group members, the participants were randomly assigned numbers at the beginning of the focus group sessions and were identified by that number in all audiotaped recordings, transcriptions of recordings, and subsequent documents including the research document itself. Transcription was done by a professional, paid transcriptionist familiar with healthcare and nursing research studies. This person was instructed that all information was confidential.

\section{Analysis}

Once the data from the recorded sessions was transcribed by a professional, paid transcriptionist, the content was analyzed by the researcher, her chairperson, and her committee members using qualitative content analysis technique. Qualitative content analysis requires review of the transcripts, examining the language within the content of the transcripts, and classifying the data into themes relevant to understanding the phenomena being studied (Hsieh \& Shannon, 2005). This method of analysis, used in this country for the past hundred years, has recently been recognized for its adaptability to health care research. Qualitative content analysis can be utilized through one of three possible approaches: conventional, directed, or summative The conventional approach was used for this study as it allows for data collection through open-ended questions, or "probes" to develop categories, or themes, derived from actual data (Hsieh \& Shannon, 2005). 


\section{CHAPTER 4: FINDINGS}

\section{Introduction}

The purpose of this qualitative study of perceived barriers to primary care access in rural, medically underserved areas (MUAs) was to identify patients' perceptions of barriers in a northern California coastal region served by one critical access hospital $(\mathrm{CAH})$, three rural health clinics, and five private primary care providers. A series of two focus group sessions yielded, by way of content analysis, several themes on access to primary care services in this geographical area (Hsieh \& Shannon, 2005). The most prominent theme was that people living in rural areas or communities have unique health care needs when compared to residents of urban or metropolitan areas. A second theme identified a perceived inability by community members to access care through their primary care providers (PCPs) for sudden, or unexpected, episodic illness or injury and that the inability to access care leads to foregone care, delayed care, or seeking care in the emergency department for nonurgent problems. The third theme, unexpected at the inception of this project, emerged during the focus group sessions and indicated that the same-day walk-in services provided at the Immediate Care Clinic were meeting the needs of patients who would otherwise have foregone care, delayed care, or sought care in the emergency department for a nonurgent problem. 


\section{Demographics of Focus Group Participants}

The two focus groups were composed of 8 participants: five females and three males. One participant was in the 30-44 years age group and the remainder were over the age of 65 . One group member had private insurance while the remainder was insured through either Medi-Cal or Medicare. All but one participant was retired or unemployed, five were unmarried whereas three were either married or in a domestic relationship, and all participants identified their race as being white or Caucasian. All participants had used the Immediate Care clinic at least once in the preceding six-month period. A set of guidelines for the sessions (see Appendix B) was developed well in advance of the selected dates and used in both sessions to help keep the discussion on track and focused on data relevant to the objectives of the project.

\section{Theme 1: People Living in Rural Areas have Unique Health Care Needs}

\section{Patients Want to be Seen as Whole and Unique Individuals}

Focus group participants described a number of encounters with providers wherein they did not feel that their unique needs were addressed. One participant stated that he and his wife have had issues with some of the providers which necessitated transferring care to a new provider while another participant expressed "disgust" with a provider who "hardly looked at me, I mean literally looking at looking at the computer instead. Didn't touch me. And I felt like a 
waste of time." Participants of the focus groups interpreted time spent on the computer as time not spent on their care: A third group member, noting that the provider spent time on the computer that should have been spent focusing on the patient, suggested the use of an audio-recorder with translation by a scribe. Another group member stated that when her regular PCP became ill and cancelled two appointments, she "finally did get an appointment, it was one of the visiting or rent-a-docs, I call it, and he was terrible. He saw me for 15 minutes exactly, all he did was listen to my heart, he didn't have my lab work, and he didn't know anything about me". This particular patient identified three areas of concern in her statement: the length of time the prover spent with her, the brevity of the physical exam, and the fact that the provider did not appear to know her past medical history including most recent lab results. She also stated that she was so disappointed that she changed from her regular PCP at the hospital clinic to another provider in private practice. She also stated that she took this matter to the hospital board.

One factor that falls into both the provider-level and the systems-level categories is the general dissatisfaction with the 15-minute appointment. The National Clinical Guideline Centre (NCGC) clinical guidelines state that health care professionals with the right attitude, and essential skills, can achieve a balance between the delivery of care in a busy environment and meeting the needs of the patient as an individual (NCGC, 2012). The consensus between the two 
groups was that it was difficult to establish trust in a provider when they were being "pumped through every 15 minutes" as one respondent stated, citing "I know when I'm in a healthcare factory and they're just pushing me through" and "it's impossible to see everybody in 15 minutes because one size does not fit all". Shortened visits can be considered under systems-level factors because reimbursement rates for office visits are declining, as demonstrated with flat rate reimbursement, and providers are frequently pressured into seeing greater numbers of patients in the same periods of time in order for their practices or organizations to remain solvent (Murphy, 2016). The Johns Hopkins Medicine Armstrong Institute for Patient Safety and Quality (2016) notes that the 15-minute appointment was developed to meet the demands of increased patient volumes and the need for clinic profitability. When providers are seeing patients every 15 minutes, it is difficult to get to root causes of patient problems, make accurate diagnoses and develop best-practice treatment plans: an issue that is concerning to patients and providers alike (Pronovost, 2016). The National Clinical Guideline Centre (NCGC) has stated that recognizing and treating the patient as an individual is an essential aspect of good patient care and leads to the improved safety, efficiency and effectiveness of health care (NCGC, 2012).In its 2012 report on improving patient experiences in adult health services, the NCGC specifically recommended allowing adequate time for quality dialogue with the patient. 


\section{Diminishing Numbers of Primary Care Providers}

David Freed of the California Health Care Foundation (CHCF) stated, in a 2011 article in the San Francisco Chronicle, that the problem of doctors retiring and not being replaced is of particular significance in Mendocino County, where half of the physicians in the county were older than 56. In the article, Dr. Marvin Trotter is quoted as saying that with fewer local primary care physicians, the county is headed for a "full-blown health care crisis" (Freed, 2011). The article further stated that most new doctors in California prefer to practice in or around San Francisco, Los Angeles, and other large urban areas because the incomes are higher and the cultural and recreational opportunities are greater. As providers retire, their patients are having to see new providers: sometimes locums or temporary providers who are not as familiar with the patient on an individual level. Section six of the National Clinical Guideline Centre (NCGC) 2012 publication on the patient experience in adult national health services is titled "Knowing the patient as an individual". This section states that being recognized and treated as a unique individual is an important part of the entire patient experience (NCGC, 2012).

All eight focus group members verbalized concern over the shrinking pool of available local providers and acknowledged that there are challenges in recruiting and retaining quality healthcare providers to the area. They were asked "Do you think that we have enough healthcare providers on the coast and what can 
be done to attract more providers to this area?" The participants shared many observations including the perception that "housing is a major issue" and that the shortage of available housing is a primary deterrent to attracting doctors, nurses, and healthcare professions to the area. Respondents noted that rentals are scarce and geared toward vacationers while the cost of purchasing a home is too high for what the area has to offer in ways of amenities. Two of the participants noted that the city and county should be tasked with creating more rentals and saleable housing. A long-time (over 30 years) resident in the group made the astute observation that "we used to have doctors who lived here because they could afford to live here - for one thing, they could afford a house - and they wanted to be here. But now, it seems like the doctors don't want to come here. Maybe it's too expensive to live here or the homes are too expensive or they prefer to live in a city environment where they can make more money".

Focus group members also expressed dissatisfaction with the practice of staffing clinics with 'locums', or temporary healthcare providers. The participant who rated her care from a locums provider as "terrible" went on to say "It's not as if they've been here a long time and they're going to stay. So I think that has a great effect on the way they treat patients. They're just passing through: I felt totally disrespected. I'm in my 80 's, so I have a few problems and he didn't deal with even one of them". This comment is rich in information. It is the perception of the patient that temporary health care providers don't feel the same connection 
to, or respect for, the community that a more permanent provider may have. This participant also acknowledges that her age and additional health problems are a real concern.

\section{Lack of Specialty and Consult Services}

Participants were asked how they felt about their ability to get specialist care if needed. The responses were numerous and emotional. A member of one group started the conversation by stating "I feel like the specialist situation is a disaster, a complete disaster. We live so far from anything else and we don't have people here that are skilled enough or diverse enough to take care of the needs of the young and of the aging population.” The fact that the next closest town with more expansive medical specialty services is over two hours away was a special concern for one participant who shared that 'since I'm in my 80 's, I've gotten very anxious about what I feel is a lack of healthcare here. And I even thought about leaving the area and going to another area where I would be closer to a hospital that is solvent, and specialists, and better healthcare although I really don't want to leave the area." This sentiment was shared by another member whose mother had a heart condition and, although the woman "would have loved for her to move here ... (but) the medical care wasn't good enough".

The group discussed the fact that, currently, a cardiologist and a urologist travel to the area two days each month to see patients on the coast. Specialty services were once offered on the coast, but are no longer obtainable. These 
services included pulmonology, dermatology, gastroenterology, endocrinology, nephrology, and neurology. One participant, who moved to the area within the past few years, stated that people in this area pay a little extra (by purchasing an annual contract) for air medical transport insurance in the event they need to be transferred emergently from the local critical access hospital to a hospital offering specialty services in another town. Another group member mentioned that he had numerous friends who had been hospitalized out of the area (because they needed specialty care) and how this geographical separation is detrimental to the recovery of the sick person who may be hours away from members of his or her support system.

A few more participants voiced the importance of having an advocate while you are hospitalized. One participant noted that a friend of hers who was hospitalized "had friends coming in daily to clean her room because the room was not being cleaned and ... staff was not keeping track of the patients who might be freezing and who might need a warm blanket". Participants cited having to travel to San Francisco (172 miles) or Sacramento (189 miles) for specialized surgeries, specifically mentioning spinal or cardiac surgery.

The groups were asked how they felt about telemedicine, such as a virtual visit with a specialist, as a possible solution for certain consultations. A few of the focus group members had experience with telemedicine and gave mixed reviews of this concept as a possible means to facilitate the need for specialty consultation. 
A participant with a background in the computer and telecommunication industry spoke of some of the capabilities of telemedicine as a measure to expand and enhance services, "augment" our current physicians, and bring needed services to the patient more easily and quickly. He further noted that the technology is present to support telemedicine, and that telemedicine may be cost effective in terms of time and expense. Another member of the group stated that he had seen telemedicine used in a hospital for stroke patients: Patients in the ED exhibiting signs of stroke had a virtual examination by a neurologist and many of these patients had good outcomes in terms of return of speech and function. A group member who admitted to having no experience with telemedicine felt that it was not as personal because the provider "can learn a lot by shaking your hand, seeing your facial expressions, and reading your body language" when he or she is in the room with the patient.

\section{Theme 2: Community Members Perceive Significant Barriers to Primary Care Access}

The reported barriers arose when these same patients sought care for unplanned medical problems. All participants reported having received regular medical screening for hypertension, diabetes, and depression as well as applicable screenings for cervical, colon, and breast cancers. Two members of one group noted that they were old enough that they were no longer candidates for routine screening colonoscopies "because of perforation problems". The youngest 
participant, who was in the 30-44 year age bracket stated that he was "about to be in the age bracket where it'll be worthwhile". This comment is relevant in that it shows that the patient has been made aware of screening guidelines. Participants shared that their providers had regularly discussed with them the recommended clinical preventative services, as identified by Healthy People 2020 (Healthy People 2020, 2018). Contrary to the findings of the 2017 study by Allen, Call, Beebe, McAlpine, and Johnson, which examined barriers to health care among adults with Medicaid insurance, the participants of these focus groups did not forego preventative care because of barriers to primary care access.

\section{Difficulty Accessing the PCP for Unexpected or Episodic Illness or Injury}

Members of both focus groups, all of whom reported having a regular PCP, were next asked to share their experiences in attempting to make an appointment for an unexpected illness or injury with their PCP. One participant stated "I wouldn't even bother calling (my PCP) ... you call your provider and they tell you that you're maybe going to see them in two to three weeks, if you're lucky" although this same participant admitted that he has had some success putting himself on the cancellation list and being seen with 24 hours. Other group members did not have experience with the cancellation list. "I normally don't call a provider for anything other than something I know I can wait two weeks for an appointment". A third respondent stated that if she needed to be seen "quickly" (which she quantified as being seen in the next week or two), she would not be 
able to see her regular PCP and would have to see another provider. A fourth group member related being very sick with bronchitis, having trouble breathing and wheezing, and being told she could be seen in a "couple of weeks". She advised the scheduler she needed to be seen "now" and "somehow or other they arranged something".

\section{Access Barriers Lead to Foregone or Delayed Care, and ED Overutilization}

Participants were asked if they could give an example of any time that they, or someone they knew, had a significant delay in receiving medical care or had gone without care because they could not get in to see their PCP. The statement "if I was bleeding - but not bleeding badly, I'd probably wait a little bit" was echoed by another group member in the other session who said "if it was a cut or rash, unless it was really scary and went on for days, I would probably deal with it myself. I'm not a medical person, but I've been around long enough". These responses are examples where the decision to delay or forego care for injuries with bleeding are being made by persons with no medical background who make reference to "bleeding - but not bleeding badly" and not seeking care unless the condition "was really scary or went on for days". Another member responded that she "would first try massage, or acupressure, or acupuncture, or a chiropractor, or talk to friends and naturalists" and also identified staff at the local health food stores as sources of healthcare information as well as the local pharmacists. 
Focus group members were then asked if they, or someone they knew, had used the ED for nonurgent problems because they could not be seen elsewhere. Several members gave the example of UTI as a minor but time-sensitive illness for which they would seek care in the ED if they were unable to see their PCP but one participant stated that the wait for care in the ED can be quite long (she cited five hours). The participants repeatedly mentioned UTI, which is a medical diagnosis requiring urine culture, when they likely meant symptoms of UTI, which can include dysuria, urinary frequency, urgency and hesitancy. Patients are frequently unable to differentiate between symptoms of a generally benign illness and those of a more serious or emergent nature.

As an example, a 66 year-old female presented to the immediate care clinic requesting an antibiotic for a "UTI". Her history and physical findings were inconsistent with UTI: she had some discomfort with urination, but no frequency or urgency. Physical exam was notable for localized lower left quadrant tenderness. A bedside urinalysis revealed no leukocytes, nitrites, or white blood cells. The nurse practitioner sent the patient to the ED for laboratory studies and diagnostic imaging, the results of which showed a perforated diverticulitis.

One participant questioned the practice of parents taking their children to the ED for minor problems on the weekends. However, she quickly acknowledged that the only other option was to wait until Monday and run the risk of not being able to get an appointment with the PCP for another two weeks. These reports are 
consistent with the findings of a study examining ED use for nonurgent complaints as a consequence inability to access primary care published in the American Journal of Medical Quality. The study concluded that both publicly and privately insured patients utilized the ED for minor complaints because they were unable to get an appointment with their provider, they had not been able to establish care with a PCP, or they had difficulty making time for an appointment during traditional business hours. Uninsured patients utilizing the ED instead of a PCP had additional barriers related to financial, insurance, or transportation factors (Hefner, et al., 2015).

\section{Theme 3: Immediate Care is Meeting the Needs of Community Members Requiring Care for Unexpected or Episodic Illness or Injury.}

The first question posed to the groups at the beginning of each session was "What would you do if you had a minor medical complaint such as a rash, earache, cough, flu, or urinary complaint, or if you had a minor injury like a sprain or strain, cut or other minor wound, or a back injury?" The unanimous response: Go to Immediate Care (the Immediate Care Clinic at North Coast Family Heath Center). Specific comments were "I would probably go to Immediate Care for that" and "I wouldn't even bother calling (my PCP), I'd just go to Immediate Care".

One participant polled her neighbors prior to coming to the focus group session and presented a list of suggestions to improve health care in the 
community: Topping the list was the recommendation that "Immediate Care should be available seven days a week from 8:00 a.m. through 8:00 p.m.” Other group members commented that if immediate care were available on weekends, even if only for half a day, "it would certainly help the community of people who have to work" and "when I came here (from out of state) and found out there was nowhere to go Saturday and Sunday for immediate care, it was like 'Huh?'”

\section{Summary of Findings}

Flaskerud, who along with Winslow first described the vulnerable populations conceptual model (VPCM), noted in 1999 that "research has shown that lack of resources, rather than the presence of risk factors, is the best predictor of illness and premature death in vulnerable populations" (Nyamathi et al., 2007, p. 6). Focus group participants in this study agreed that they want to be seen as whole and unique individuals by providers they trust: providers who are permanent, rather than temporary, members of the community and who will spend time listening to them. They understand that living in a rural area present a unique group of challenges to quality health care including a diminishing number of providers and a lack of local specialty and consult services. While participants stated they were able to access their PCP for routine and preventative care, they unanimously perceived an inability to access primary health care services for sudden, or unexpected, episodic illness or injury which, prior to the establishment of an immediate care clinic, led to foregone care, delayed care, or seeking care in 
the emergency department for nonurgent problems. All focus group participants stated that their health care needs for these medical conditions had been met by the immediate care clinic. 


\section{CHAPTER 5: DISCUSSION}

The purpose of this qualitative study was to identify, using conventional content analysis methods, the perceived barriers to primary care access in one rural, medically underserved area of northern California utilizing focus groups comprised of community members who accessed the health care system. While the Institute of Medicine describes quality health care as care that is safe, timely, effective, efficient, equitable, and patient-centered (AHRQ, 2016), achieving this level of quality is difficulty for rural communities as they have less resource availability then urban and suburban communities. The review of literature and the findings of the focus group sessions in this study support the theory that barriers in accessing primary care services for simple episodic illnesses or minor injuries result in care that is inconsistent with the IOM's quality domain descriptors, leading patients to delay care, forego care, or inappropriately seek care in the ED for a relatively minor complaint. The literature identifies barriers to access, as perceived by the patient, at the personal, provider, and systems levels (Allen, et al., 2017) and offers multiple long-term solutions to the issues of recruiting and retaining more primary care providers to rural communities, but does not offer any short-term solutions to this problem that affects rural community members every day. The immediate care model appears to be one prototype that is showing success in improving patient outcomes by offering health care services that are safe, timely, effective, efficient, equitable, and patient-centered. 


\section{Comparison of Urban and Rural Health Care Demographics}

\section{The Centers for Disease Control and Prevention (CDC) Classifications}

The CDC National Center for Health Statistics (NCHS) classifies

populations into metropolitan (urban) and nonmetropolital (rural) categories to better monitor the health of urban and rural residents. Metropolitan, or urban, areas are further categorized as (a) large central metropolitan areas with populations of 1 million or more, (b) medium metropolitan areas with populations of 250,000-999,999, and (c) small metropolitan areas, small towns or suburbs with populations of 50,000-249,000. Nonmetropolitan, or rural, areas include (a) micropolitan areas: rural counties where there may be a small urban cluster of 10.000-49,999 residents, and (b) noncore areas, counties that did not qualify as micropolitan areas (Hing \& Hsiao, 2012).

Mendocino County is classified as a micropolitan area. Sonoma County, directly to the south, is a medium metropolitan area and Napa County, to the southeast, is a small metropolitan area. The NCHS Data Brief further stated that the ability to obtain primary health care services depends on the supply of PCPs per capita and the availability of physician assistants or nurse practitioners within the PCP's practice: the number of PCPs per 100,000 population in large metropolitan areas is 53.3 while the number of PCPs per 100,000 population in nonmetropolitan areas is 39.8. The average number of PCPs available per 100,000 
population across all areas was 46.1 while the number of specialists was much higher: 65.5 per 100,000 population (Hing \& Hsiao, 2012).

Compared to metropolitan areas, nonmetropolitan areas have higher ageadjusted rates of death from the five leading causes of death in the United States: heart disease, cancer, unintentional injury, chronic lower respiratory disease and cerebrovascular accident or stroke (Moy et al., 2017). Differences between health care and health indicators in urban and rural areas are not favorable to rural communities in the U.S. (see Table 1). All but one member of the focus groups was over the age of 65 which is a reflection of the county demographics where $19.1 \%$ of the population are age 65 and older (SuburbanStats, 2019). Nationally, $50 \%$ more of the population over the age of 65 live in rural, rather than urban areas (National Rural Health Association, 2016).

Table 1

\section{Differences in Rural and Urban Health Care Indicators}

\begin{tabular}{|l|c|c|}
\hline Indicator & Rural & Urban \\
\hline Percentage of population & 19.3 & 80.7 \\
\hline Physicians per 100,000 population & 39.8 & 53.3 \\
\hline Specialists per 100,000 population & 30 & 263 \\
\hline Dentists per 100,000 population & 22 & 30 \\
\hline Percentage of population aged 65 and older & 18 & 12 \\
\hline Percentage of populations living in poverty & 18.1 & 15.1 \\
\hline Potentially excess deaths: heart disease & 42.6 & 27.8 \\
\hline Potentially excess deaths: cancer & 24 & 14 \\
\hline Potentially excess deaths: unintentional injury & 57.5 & 39.2 \\
\hline $\begin{array}{l}\text { Potentially excess deaths: chronic lower respiratory } \\
\text { disease }\end{array}$ & 54.3 & 30.9 \\
\hline Potentially excess deaths: CVA & 39 & 26 \\
\hline
\end{tabular}

All information in this table is from the National Rural Health Association and the Centers for Disease Control and Prevention MMWR Surveillance Summary (Moy et al., 2017). 


\section{Health Resources \& Services Administration (HRSA) Designations}

HRSA is the entity tasked with designating geographical areas and populations with a lack of access to primary care services as Medically Underserved Areas and Populations (MUA/Ps). A Medically Underserved Area (MUA) is a strictly geographic definition of an entire county, a group of neighboring counties, a group of urban census tracts, or a group of county or civil divisions where a shortage of primary care health services exists (HRSA, 2016). A Medically Underserved Population (MUP) is a sub-group of people living within a geographic area already designated as having a shortage of primary care health services. These groups face additional cultural, linguistic, or economic barriers to health care and may include the homeless, low-income residents, Medicaideligible residents, Native Americans, or migrant farmworkers (HRSA, 2016). A weighted calculation known as the Index of Medical Underservice (IMU) is used to designate MUA/Ps and uses the following factors to make the designation: the population to provider ratio, the percent of the population living below the federal poverty level, the percent of the population over the age of 65 , and infant mortality rates (HRSA, 2016). Mendocino County has been designated a MUA (HRSA, 2016). Mendocino County, when compared to the rest of the state of California, meets several of the criteria factored into the IMU calculation (see Table 2). 
Table 2

Comparison of County, State, and U.S. Demographics

\begin{tabular}{|c|c|c|c|}
\hline Indicator & Mendocino County & State of California & United States \\
\hline \multicolumn{4}{|l|}{ Age of Population \% } \\
\hline $0-9$ & 12 & 12 & 12 \\
\hline $10-19$ & 11 & 13 & 13 \\
\hline $20-29$ & 11 & 15 & 14 \\
\hline $30-39$ & 13 & 14 & 13 \\
\hline $40-49$ & 11 & 13 & 12 \\
\hline $50-59$ & 14 & 13 & 13 \\
\hline $60-69$ & 14 & 10 & 11 \\
\hline $70-79$ & 9 & 6 & 7 \\
\hline $80+$ & 5 & 3 & 4 \\
\hline Median Age & 42.7 & 36.5 & 38.1 \\
\hline \multicolumn{4}{|l|}{ Race and Ethnicity \% } \\
\hline White & 65 & 37 & 61 \\
\hline Hispanic & 25 & 39 & 18 \\
\hline Black & 1 & 5 & 12 \\
\hline Native American & 3 & 0 & 1 \\
\hline Asian & 2 & 14 & 6 \\
\hline Pacific Islander & 0 & 0 & 0 \\
\hline Other & 0 & 0 & 0 \\
\hline Two or more & 4 & 3 & 2 \\
\hline Per Capita Income & $\$ 29,170$ & $\$ 35,046$ & $\$ 32,397$ \\
\hline $\begin{array}{l}\text { \% Persons Living Below } \\
\text { Poverty Level }\end{array}$ & 19.1 & 15.1 & 14.6 \\
\hline Number Homeless & 1,242 & 129,972 & 550,000 \\
\hline $\begin{array}{l}\text { Infant Mortality Rate per } \\
1000 \text { live births }\end{array}$ & 4.3 & 4.5 & 6 \\
\hline $\begin{array}{l}\text { Health Care Providers per } \\
100,000 \text { population }\end{array}$ & 90 & 135 & 157 \\
\hline Median Home Value & $\$ 409.900$ & $\$ 509,400$ & $\$ 217,600$ \\
\hline
\end{tabular}

All information in this table is from Census Reporter, the United States

Interagency Council on Homelessness, and Healthy Mendocino,

\section{Project Outcomes}

The majority of studies to date cite multiple barriers to primary healthcare access for routine preventative medical care. Allen, et al. (2017) specifically list 1) personal issues such as family responsibilities, work responsibilities, or lack of childcare availability, 2) problems with the individual provider including language 
barriers, cultural or religious lack of understanding, lack of trust in the provider, or an office environment which seemed "unwelcoming", and 3) system-specific factors related to coverage, financial barriers, inability to get an appointment, inability to see the provider of choice, inability to be seen during regular office hours, and not being familiar with the location of the office (Allen, et al., 2017). While all focus group participants in this study reported having a primary care provider whom they saw on a regular basis for preventative care and chronic medical problems, and all participants reported having had clinical preventive services, including screening for the prevention or early detection and treatment of colorectal cancer, breast cancer, and cervical cancer (leading health indicators identified by Healthy People 2020) performed where appropriate for age and gender, their barriers to care became apparent when they sought care for an unplanned or episodic illness or injury. Every member of the focus groups reported that, prior to the existence of the immediate care clinic, they would have experienced delays in care for unplanned illnesses or injuries, citing delays of up to three weeks.

None of the respondents answered that they had experienced personal issues as barriers to care, although one participant noted her daughter works all week and that if she takes time off for a medical appointment "she loses money when she has to see a doctor and that's not right". The same woman also stated "if you're talking to single parents who are working full-time and raising children, 
they might lose a job if they're not on the job from 8:00 - 5:00 every day, or they might not have a car or money for gas. So there are circumstances, I think, that would affect other people differently". A 2008 study by the National Opinion Research Center at the University of Chicago found that $16 \%$ of workers in lowwage jobs reported that they, or a family member, had been fired, suspended, punished, or threatened with firing for missing work because of personal or family illness (Smith, 2008).

At the provider level, no discrimination or cultural issues were identified by either group and members specifically stated that they had no knowledge of anyone in the area experiencing discrimination or a lack of cultural respect. However, lack of trust in the provider was cited by half of the group members and their responses indicated that the 15-minute appointment was the reason for this mistrust: they did not feel that 15 minutes was enough time for a provider to properly evaluate and treat them. One patient, who was not a member of the focus groups, presented to Immediate Care for care of a large second degree burn to her forearm. She stated that she had seen her private physician earlier in the day for a well-women exam. At the end of her 30-minute visit, she attempted to show her PCP the burn and was reportedly told that her visit had already "run over-time" and she would need to "go to Immediate Care" to have the burn looked at. In her visit to the immediate care clinic, the provider spent time getting the history, examining the burn, performing wound care, instructing the patient on home 
wound care, providing her with the supplies needed for wound care and a prescription for a topical antimicrobial medication, educating her on what to watch for in the event of complications like infection, and giving her follow up instructions.

The immediate care clinic profiled in this study is meeting the needs of community members seeking care for unplanned illness or injury, regardless of their insurance or payment type and regardless of their regular PCP assignment. This model of care offers same-day care, with no appointment necessary, for patients experiencing acute, non-emergent medical problems and minor injuries when their primary care provider (PCP) is unavailable or if the patient has no PCP. The care provided at an immediate care clinic has been compared to that received from a PCP, but more accessible and convenient for the patient; unlike an urgent care clinic which is generally equipped to handle non-life-threatening emergencies along with basic health care services (George Washington Medical Faculty Associates, 2014).

During the six-month period from August 1, 2018 through January 31, 2019, a total of 1868 patients were seen in Immediate Care between the hours of 9:00 a.m. and 6:00 p.m., Monday through Friday. IBM SPSS was used to run frequencies analyses of two demographic variables collected from these 1868 patient encounters. The first variable analyzed was insurance type: Medicare, Medi-Cal, Blue Cross, Blue Shield, commercial, government payer, or uninsured 
(see Figure 1). The largest number of patients, over $44 \%$, were covered by

Medicare or Medicare Managed Care. The next largest group, at 30\%, was Blue

Cross or Blue Shield followed by Medi-Cal and Medi-Cal Managed Care at 14\%.

Six percent of patients were uninsured and six percent were covered by

commercial or government payers.

Figure 1

Patients Seen in Immediate Care by Insurance Type (8/1/2018 through 1/31/2019)

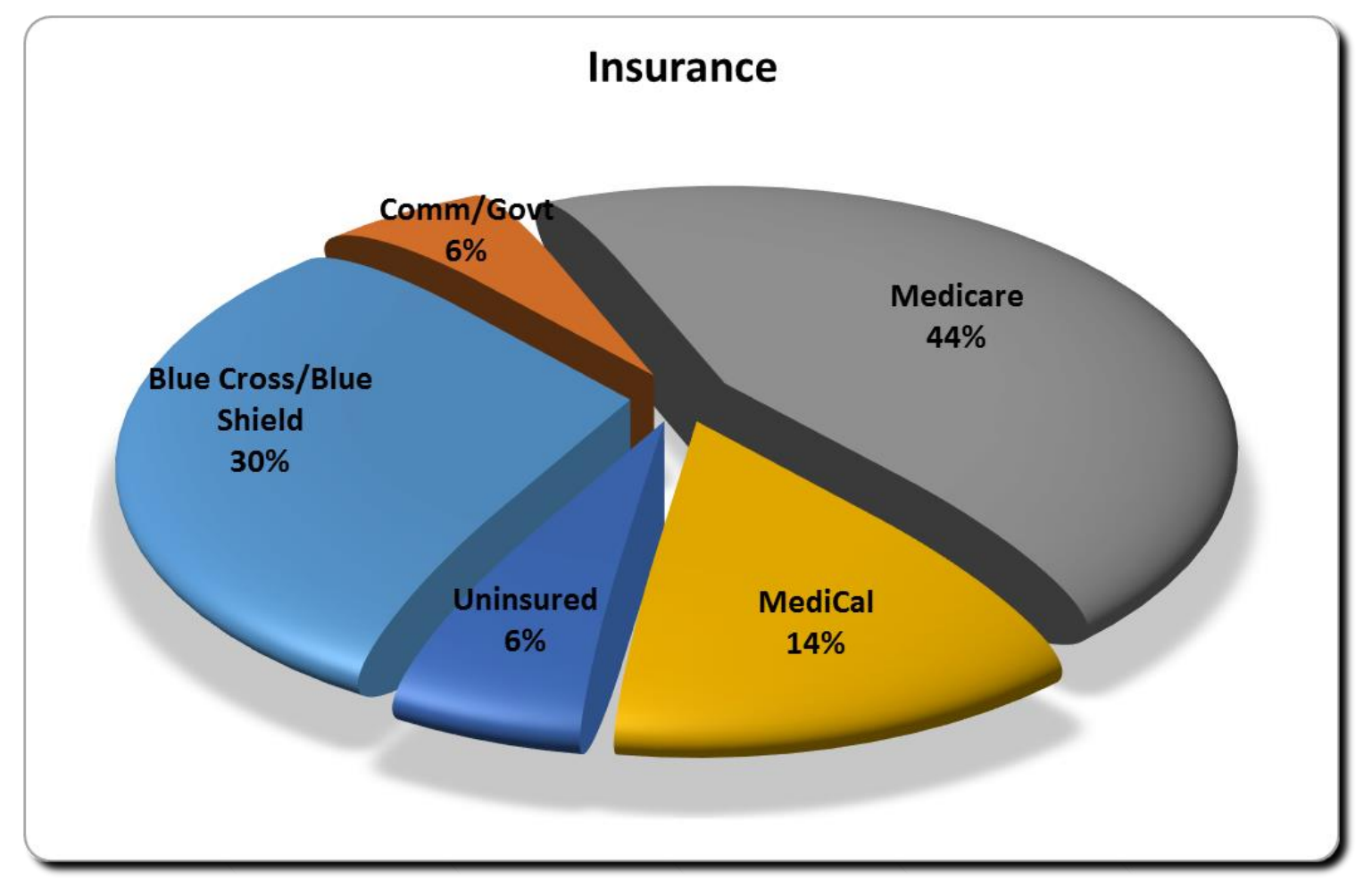

n=1868 Created in Microsoft Office Excel

The second variable analyzed the provider types (see Figure 2). Nearly half of the patients seen in Immediate Care over this six-month period, almost 48\%, reported seeing one of the seven PCPs (four physicians, two nurse practitioners, and one physician assistant) who practice in the same rural health clinic where 
Immediate Care is located for their primary healthcare. Nineteen percent were regular patients at one of the other two rural health clinics in the area. (All three rural healthcare clinics are located within a quarter-mile of the area's only hospital.) Just over 17\% of patients reported having no PCP. Eight percent of patients using the services at Immediate Care were established with one of the area's five providers who are in private practice (three physicians and two nurse practitioners) and the remaining eight percent of patients had providers who were outside the local geographical area.

Figure 2

Patients Seen in Immediate Care by Primary Care Provider (8/1/2018 through 1/31/2019)

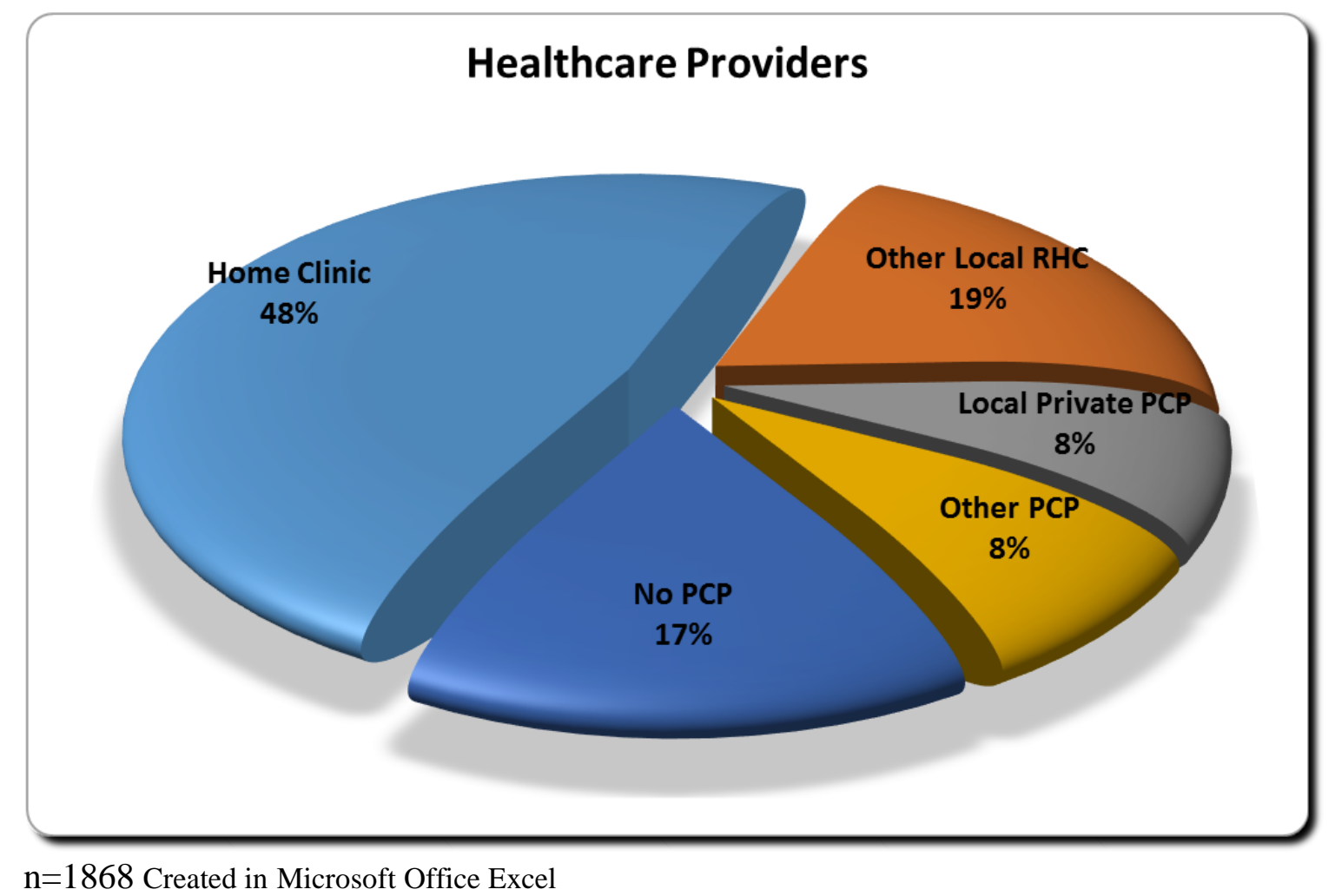


The results of these statistical analyses, combined with the responses of the focus group participants, yielded three relevant concepts. First, patients with minor illnesses or injuries are choosing to visit Immediate Care when they are unable to see their own PCP. Second, patients are visiting Immediate Care whether they are publicly insured, privately insured, or uninsured. And third, patients are visiting Immediate Care regardless of whether or not they have a primary care provider. The logical interpretation of these findings is that Immediate Care is providing a viable solution to the problem of foregone care, delayed care, and ED utilization for nonurgent problems. A patient treated in the Immediate Care clinic posted the following review of the care that she received on the clinic website: "...FNP provided the best care I've received in five years. She was thorough, intelligent, obviously trained, knowledgeable, (and) professional while being humanly warm. I am thoroughly pleased with her and the help she provided me" (Mendocino Coast District Hospital, 2018).

\section{Strengths and Limitations}

The most notable strength of the study lies in the analysis of the qualitative content of the focus group sessions which not only echoed many of the barriers to care noted in the literature review, but also identified immediate care as a real solution to the problem of access to healthcare for episodic complaints. Focus groups proved to be an effective method to explore the participants' perceptions of barriers to health care access as it allowed the group members to share their own 
experiences and build on shared experiences. The strength of the study is further reinforced by the fact that the researcher is also the lead health care provider in the immediate care clinic and is involved in direct patient care 32 hours per week, allowing her to integrate the findings of published studies with actual practice.

The small sample size, combined with the homogeneity of participants with regard to age, race, ethnicity, and insurance type, was the most notable limitation of the study. Although the participants were engaged and enthusiastic, eight is minimal for qualitative research using focus groups (Stewart \& Shamdasani, 2015). Additional data may have been gathered from younger participants, participants from more diverse racial and ethnic backgrounds, and more participants who were employed on a full-time basis and faced the challenge of making health care appointments during traditional work hours.

\section{Nursing Implications}

Advanced practice nurses (APRN), especially those with family practice and emergency department experience, are in a prime position to provide safe, timely, effective, efficient, equitable, and patient-centered care to community members who would otherwise not receive it. The immediate care model is an easily implemented and cost effective strategy to provide this care. The APRN is knowledgeable in evidence-based practice and has the clinical expertise and experience to provide care based on best practice. In addition to critical thinking, clinical judgement, and clinical decision making skills, the experienced APRN has 
the additional qualities, developed through nursing practice, of strong communications skills with patients and families as well as other health care professionals.

As of 2019 there are 34 Critical Access Hospitals (CAHs) in the state of California and 1,348 in the entire United States (Rural Health Information Hub, 2019). CAH emergency departments across the country struggle with surges in patient flow: in EDs with single physician coverage, one critically ill patient may overwhelm all available resources (physician, nursing, respiratory therapy, diagnostic imaging, laboratory) for prolonged periods of time which results in low-acuity patients having extended wait times (Welch, 2017). In facilities where the physical plant cannot accommodate a fast-track or low-acuity throughput process, these patients will continue to wait - leading to a delay in care or, if they are unable to keep waiting, foregone care.

Certain new models of ambulatory care including free-standing urgent care clinics, retail clinics, and electronic visit websites have been seen as threats in continuity of care: a disruptive innovation which may erode the relationship between the patient and the primary care provider (Ladapo \& Chokski, 2014). Services provided at this immediate care clinic, frequently not provided in other convenient care or urgent care settings, were developed to enhance communication between health care team members and to improve patient outcomes. These services make this clinic stand out when compared to other 
immediate or convenient care clinics. For the patient reporting that he or she is already established with a primary care provider (PCP), a copy of the encounter document is faxed to that provider. For patients reporting that they do not have a primary care provider, they will be given a list of area providers or, if they prefer, an appointment with a PCP in the same practice will be made during the visit. If a patient does not have health insurance, an access coordinator will attempt to see if the patient is eligible for any of the public insurance plans and assist with paperwork. If the APRN determines that a patient would benefit from specialty consultation, such as orthopedic surgery or otolaryngology, the referral can be made during the visit rather than sending the patient back to the PCP for referral.

\section{Conclusions}

Physician supply and demand studies have projected that by the year 2025, there may be a shortage of as many as 31,000 adult primary care providers in the U.S (Long, et al., 2016). Reasons for this projected shortage include the fact that fewer medical residents are planning to go into primary care or internal medicine, opting instead to pursue specialty practices (Long, et al., 2016), there is a shortage of healthcare providers through attrition of practicing providers, and it is difficult to recruit and retain new providers to rural areas (Ewing \& Hinkley, 2013).

Permanent solutions to the problem will not come quickly.

During the Obama administration, the U.S Department of Health and Human Services (HHS), recognizing the impending shortage of primary care 
providers in rural areas, was tasked with improving recruitment and retention of health care providers in rural areas through the "Improving Rural Health Care Initiative". Several programs oriented toward this goal were developed by the Health Resources and Services Administration (HRSA). Funding opportunities like the Primary Care Training and Enhancement Program have become available to hospitals in rural communities and, while these programs may ultimately benefit the rural community, these benefits are not likely to be realized for many years. Many rural hospitals and clinics do not have staff with the grant-writing expertise of experience to apply for these programs (HHS, 2012).

Recruitment and retention of health care providers to rural communities can be further compounded by perceptions of the providers themselves. Medical residents have cited professional isolation, lower salaries, the challenges of primary care medicine, and concern for lack of ancillary mental health and social services support in rural communities (Long, et al., 2016). In a study of primary care medicine residents, a lower salary was one factor that the residents had initially felt was a fair compromise for the benefit of living in a rural area, but by the end of the study, the residents felt that the lower salaries, coupled with the negative elements of rural practice including stress, personal and professional isolation, and fear of burnout expressed by their mentors deterred them from pursuing practices in rural areas (Long, et al., 2016). A 2013 study by Farmer, Prior, and Taylor used a capitals framework to link rural health services to 
community sustainability. Economic, social and human capitals were analyzed, using measurable indicators, and applied to individuals and institutions to show the added-value contributions of health services. The contributions included jobs for educated, knowledgeable, and skilled community members, a location for people to become skilled, personal and institutional consumption of locally produced goods and services including schools and real estate, attracting new community members while retaining older residents, and helping to maintain a diverse local population (Farmer, Prior, \& Taylor, 2013).

The use of telemedicine should be considered and may be attractive to the provider with concerns about lack of profession support. Other factors including lack of available or affordable housing, few employment opportunities for spouses or partners, limited school options for children, and a lack of cultural outlets (Cohen, 1998). Some of these factors, such as suitable housing, can be addressed with community leaders while other factors will remain deterrents to providers and their families considering relocation to a rural area.

The $20 \%$ of the U.S. population living in rural communities who are being cared for by only $10 \%$ of physicians (Hospital \& Health Networks, 2016) need options when they experience minor illness or injuries. Delayed care, foregone care, and use of the ED are not efficient or equitable solutions. Prompt, competent, evidence-based treatment provided in a timely manner is a solution and immediate care clinics like the one profiled in this study can provide that care: in many cases 
with resources that are already available. A recent letter to the editor in the local newspaper where the clinic is located titled 'Immediate Care Clinic a Keeper' reads "I can't tell you how thankful I am that [the hospital] provides an immediate care walk-in clinic. I've used their service twice in the last three months. If you are a 'self-pay', as I am it is really very inexpensive...I do know that this clinic has exceptionally fine nurse practitioners and is a much-needed addition to health care options here on the coast.” (Mariana, 2019). In the words of R.L. Cizek (personal communication, April 17, 2019), "Immediate Care is the best thing to happen to health care in this town". 


\section{REFERENCES}




\section{REFERENCES}

Agency for Healthcare Research and Quality, (2016). The six domains of health care quality. Retrieved from https://www.arhq.gov/professionals/qualitypatient-safety/talkingquality/create/sixdomains.htm

Allen, E. M., Call, K. T., Beebe, T. J., McAlpine, D. D., \& Johnson, P. J. (2017). Barriers to care and health care utilization among the publicly insured. Medical Care, 55, 207-214. https://doi.org/10.1097/MLR.0000000000000644

American Academy of Nurse Practitioners. (2018). State Practice Environment. Retrieved from https://www.aanp.org/advocacy/state/state-practice-environment Barbour, R. S. (2001). Checklists for improving rigour in qualitative research: a case of the tail wagging the $\operatorname{dog}$ ? $B M J, 322,1115-1117$. doi: 10.1136/bmj.322.7294.1115.

Cohen, J.J. (1998). Why don't doctors go where they're needed? Retrieved from http://www.ruralmedicaleducation.org/why_docs_dont.htm

Dixon, E.L., Strehlow, A.J., Davis, C.M., Copeland, D. Jones, T., Robinson, L.A., ...Flaskerud, J.H. (2007). Generating science by training future scholars in nursing research addressing the needs of vulnerable populations. In Annual Review of Research, 25. 161-187. https://doi.org/10.1891/07396686.25 .1 .161 
Ewing, J., \& Hinkley, K. N. (2013). Meeting the primary care needs of rural America: examining the role of non-physician providers. Retrieved from http://www.ncsl.org/dicuments/health/RuralBrief313.pdf

Farmer, J., Prior, M., \& Taylor, J. (2013). A theory of how rural health services contribute to community sustainability. Social Science \& Medicine, 75(2012), 1903-1911. http://dx.doi.org/10/1016/jsocimed.2012.06.035

Flaskerud, J.H. \& Winslow, B. J. (1998). Conceptualizing vulnerable populations health-related research. Nursing Research, 47(2), 69-78. Retrieved from http://journals.lww.com/nursingresearchonline/Abstract/1998/03000/ Conceptualizing_Vulnerable_Populations.5.aspx

Freed, D. (2011, January 11). As doctors age, small towns face critical shortages. San Francisco Chronicle: SF Gate. Retrieved from https://www.sfgate.com/health/article/As-doctors-age-small-towns-facecritical-shortage-2534487.php

George Washington Medical Faculty Associates. (2014). Urgent vs. immediate care: Is there a difference? Retrieved from https://gwdocsipc.com/urgentvs-immediate-care-is-there-a-difference/

Health Resources \& Services Administration. (2016). Medically underserved areas and populations. Retrieved from https://bhw.hrsa.gov/shortagedesignation/muap

Healthy Mendocino. (2018). Mendocino County indicators. Retrieved from 
http://www.healthymendocino.org/index.php?module=indicators\&controlle $\mathrm{r}=$ index\&action $=$ dashboard $\&$ alias $=$ alldata\&locale $\mathrm{Id}=260$

Healthy People 2020. (2018). https://www.healthypeople2020.gov/2020/leadinghealth-indicators/2020-lhi-topics/Clinical-Preventative-Services

Healthy People 2020. (2018). https://www.healthypeople.gov/2020/leading-healthindicators/2020-lhi-topics/Access-to-Health-Services

Hefner, J.L., Wexler, R., \& McAlearney, A.S. (2015). Primary care access barriers as reported by nonurgent emergency department users: implications for the US primary care infrastructure. American Journal of Medical Quality, 30, 135-140. https://doi.org/10.1177/1062860614521278

Hing, E. \& Hsaio, C. (2012). State variability in supply of office-based primary care providers: United States, 2012. Retrieved from https:// www.ruralhealthweb.org/NRHA/media/Emerge_NRHA/PDFs/db151.pdf

Hospital \& Health Networks. (2016, January 21). Rural physician shortage demands innovative solutions. Retrieved from https://www.hhnmag.com/articles/6881-rural-physician-shortage-demandsinnovative-solutions

Hsieh, H. \& Shannon, S.E. (2005). Three approaches to qualitative content analysis. Qualitative Health Research, 15(5), 1277-1288. doi: $10.1177 / 1049732305276687$ 
Ladapo, J. \& Chokski, D. (2014). Continuity of care for chronic conditions: Threats, opportunities, and policy. Retrieved from https://www.healthaffairs.org/do/10.1377/hblog20141118.042672/full/

Leight, S. B. (2003). The application of a vulnerable populations conceptual model to rural health. Public Health Nursing, 20, 440-448. https://doi.org/10.1046/j.1525-1446.2003.20604.x/full

Long, T., Chaiyachati, K., Bosu, O., Sirdar, S., Richards, B., Garg, M., ... Huot, S. (2016). Why aren't more primary care residents going into primary care? A qualitative study. Journal of Internal Medicine, 31, 1452-1459. https://doi.org/10.1007/s11606-016-3825-9

Mareno, N. (2016). Applying middle-range concepts and theories to the care of vulnerable populations. In M. deChesnay \& B. A. Anderson (Eds.), Caring for the vulnerable: Perspectives in nursing theory, practice, and research (4th ed., pp. 117-139). New York, NY: Jones \& Bartlett Learning.

Mariana, L. (2019, March 21). Immediate care clinic a keeper. Fort Bragg Advocate-News. [Editorial].

Medicare.gov. (2019). Hospital compare. Retrieved from https://www.medicare.gov/hospitalcompare/results.html\#dist=200\&state=C $\mathrm{A} \&$ county $=$ MENDOCINO\&lat $=0 \& \operatorname{lng}=0$

Mendocino Coast District Hospital. (2017). District service area. Retrieved from http://www.mcdh.org/district-service-area/ 
Mendocino Coast District Hospital. (2018). North Coast Family Health Center:

Testimonials. Retrieved from http://www.mcdh.org/north-coast-familyhealth-center/\#1471893307355-a717d1f4-0cc9

Mortensen, K. (2014). Access to primary and specialty care and emergency department utilization of Medicaid enrollees needing specialty care. Journal of Health Care for the Poor and Underserved, 25, 801-813. ttps://doi.org/10.1053/hpu.2014.0097

Moy E., Garcia M.C., Bastian B., Rossen, L.M., Ingram, D.D., Faul, M., . . . Iademarco, P.F. (2017). Leading Causes of Death in Nonmetropolitan and Metropolitan Areas: United States, 1999-2014. MMWR Surveillance Summaries, 2017;66(SS-1):1-8 doi:http://dx.doi.org/10.15585/mmwr.ss6601a1 Murphy, M. (2016). Physician reimbursement: why it matters for the future of American health care. Medical Scribe Journal. Retrieved from https://www.scribeamerica.com/blog/physician-reimbursement-why-itmatters-for-the-future-of-american-health-care/

National Clinical Guideline Centre. (2012) Patient experience in adult NHS services: Improving the experience of care for people using adult NHS services. Retrieved from https://www. ncbi.nlm.nih.gov/books/NBK115230/pdf/Bookshelf_NBK115230.pdf 
National Rural Health Association. (2016). About rural health care. Retrieved f from https://www.ruralhealthweb.org/about-nrha/about-rural-health-care Nyamathi, A., Koniak-Griffin, D., \& Greengold, B. A. (2007). Development of nursing theory and science in vulnerable populations research. In J. J. Fitzpatrick (Ed.), Annual Review of Nursing Research, (pp. 3-25). New York: Springer Publishing Company, LLC.

Office of Statewide Health Planning and Development. (2015). Shortage designation program. Retrieved from https://oshpd.ca.gov/HWDD/Shortage-Designation-HPSA.html

Palinkas, L. A., Horwitz, S. M., Green, C. A., Wisdom, J. P., Duan, N., and Hoagwood, K. (2015). Purposeful sampling for qualitative data collection and analysis in mixed method implementation research. Administration and Policy in Mental Health, 42(5), 533-544. doi: 10.1007/s10488-013-0528-y

Partnership Health Plan of California. (2019). MediCal Provider Directory: Mendocino County. Retrieved from http://partnershiphp.org/Providers/Medi- Cal/Documents/ Provider\%20Directory/MCMendoProDir.pdf

Pronovost, P. (2016). The risks of the 15-minute doctor's appointment. Retrieved from https://armstronginstitute.blogs.hopkinsmedicine.org/2016/04/21/therisks-of-the-15-minute-doctors-appointment/ 
Rawlett, K. E. (2011). Analytical evaluation of the health belief model and the vulnerable populations conceptual model applied to a medically underserved, rural population. International Journal of Applied Science and Technology, 1, 12-21. Retrieved from http://www.ijastnet.com/journals/Vol._1_No._2\%3b_April_2011/3.pdf Rural Health Information Hub. (2019). Healthcare access in rural communities. Retrieved from https://www.ruralhealthinfo.org/topics/healthcare-access

Singh, R., Scott, H., Krueger, K., \& Bush, E. J. (2018). Healthcare engagements and encounters in a rural state: A focus group study. Innovations in Pharmacy, 9(1). doi:10.24926/iip.v9i1.944

Smith, T. (2008). Paid sick days: A basic labor standard for the $21^{\text {st }}$ century. Retrieved from http://www.norc.org/PDFs/publications/PaidSickDaysReport.pdf Stanford School of Medicine. (2010). Rural California fact sheet. Retrieved from http://ruralhealth.stanford.edu/healthpros/factsheets/downloads/rural_fact_sheet_1.pdf

Stewart, D. W., \& Shamdasani, P. N. (2015). Analyzing focus group data. In D. W. Stewart (Ed.), Focus Groups: Theory and Practice (3rd ed., 115-140). Thousand Oaks, CA: Sage Publications, Inc.

SuburbanStats.com. (2019). Population demographics for Mendocino County, California in 2019,2018 . Retrieved from 
https://suburbanstats.org/population/california/how-many-people-live-inmendocino-county

Sun, J.K. \& Smith, J. (2017). Self-perceptions of aging and perceived barriers to care: Reasons for health care delay. The Gerontologist, 57, 216-226. https://doi.org/10.1093/geront/gnx014 United States Interagency Council on Homelessness. (2019). Homelessness statistics by state. Retrieved from https://www.usich.gov/tools-foraction/map

United States Department of Health \& Human Services. (2012). Office of Rural Health Policy rural guide to health professions funding. Retrieved from https://www.hrsa.gov/sites/default/files/ruralhealth/pdf/ ruralhealthprofessionsguidance

United States Interagency Council on Homelessness. (2018). California Homelessness Statistics. Retrieved from https://www.usich.gov/homelessness-statistics/ca/

U.S. Health Policy Gateway. (2014). ACA and physician shortage. Retrieved from http://ushealthpolicygateway.com/vii-key-policy-issues-regulation-andreform/patient-protection-and-affordable-care-act-ppaca/ppaca-researchand-analysis/ppaca-impact-on-access/impact-on-access-to-care/physicianshortage/ 
Welch, S. (2017). Patient flow improvements to boost efficiency in small emergency departments. Retrieved from https://www.acepnow.com/article/patient-flow-improvements-boostefficiency-small-emergency-departments

Zip-codes.com. (2017). Mendocino County, CA ZIP codes. Retrieved from https://www.zip-codes.com/county/ca-mendocino.asp 
APPENDICES 
APPENDIX A: CONSENT FORM 


\section{APPENDIX A}

\section{CONSENT FORM}

You are invited to voluntarily participate in a study conducted by Suzanne Hewitt, a Family Nurse Practitioner (FNP) at North Coast Family Health Clinic and a doctoral student at California State University, Fresno. We hope that the results of this study will help us to learn what members of this community identify as barriers to healthcare access. You were selected as a possible participant in this study because you are a member of this community and your opinions are important as we work toward improving access to regular, reliable healthcare.

If you decide to participate, Ms. Hewitt and her associate Dr. Lilo Fink will guide a conversation in a small group of 4-6 community members to encourage dialogue among the group members on the subject of health care in our community and how we can make it easier for our community members to receive healthcare. We will be having three of these focus group interviews, each session will take place in at the Fort Bragg library last 60-90 minutes. You are only being asked to attend ONE of the sessions. The sessions will be tape-recorded and group members will not be identified by name in either the tapes or the written summary (transcription) of the tapes.

We don't anticipate any risks associated with your participation in the study. Any opinions given or suggestions made during the group sessions will be anonymous and your personal information will not be published. There is always the possibility that you will know, or know of, a fellow group member and if you feel the least bit uncomfortable, you may join another group at another time or withdraw from the study. We have tried to make the setting as comfortable as possible and, as a token of our appreciation, you will be given a $\$ 10.00$ gift card. We cannot guarantee, however that you will receive any other benefits from this study other than the knowledge that you are helping to improve healthcare in our community.

Any information that is obtained in connection with this study and that can be identified with you will remain confidential and will be disclosed only with your permission or as required by law. If you give us your permission by signing this document, the information that you furnish will be used in the research section of Ms. Hewitt's doctoral project: Identifying Barriers to Primary Care Access in Rural, Medically Underserved Areas. Upon completion of the project, all records including documents and tapes will be destroyed. For the duration of the study, documents will be stored in a locked drawer under Ms. Hewitt's supervision.

Your decision whether or not to participate will not prejudice your future relations with California State University, Fresno, North Coast Family Health Center, or the Mendocino Coast District Hospital. If you decide to participate, you are free to withdraw your consent and to discontinue participation at any time without penalty. The Committee for the Protection of Human Subjects at California State University, Fresno has reviewed and approved the present research.

Signature of this Consent Form also gives Ms. Hewitt permission to contact you after the interview to answer any questions that may arise, if necessary. You will be given a copy of this form to keep.

If you have any questions, please ask us. If you have questions later, Ms. Hewitt will be happy to answer them. She may be reached on her mobile phone at (707) 357-5602. Questions regarding the rights of research subjects may be directed to Dr. Kris Clarke, Chair, CSU Fresno Committee on the Protection of Human Subjects, (559) 278-2985.

YOUR ARE MAKING A DECISION WHETHER OR NOT TO PARTICIPATE. YOUR SIGNATURE INDICATES THAT YOU HAVE DECIDED TO PARTICIPATE, HAVING READ THE INFORMATION PROVIDED ABOVE.

Date

Signature of Witness (if any)

\section{Signature}

\section{Signature of Investigator}


APPENDIX B: FOCUS GROUP GUIDELINES 


\section{APPENDIX B \\ FOCUS GROUP GUIDELINES}

0000-0010

0010-0015

0015-0020

0020-0025

0025-0030

\section{Introductions}

- Thank you for attending

- Housekeeping items

- Purpose and goals, confidentiality, ground rules

- Consent forms, assignment of identifying numbers

\section{Opening Question - All}

- What would you do if you had a minor medical complaint (rash, earache, cough, flu, urinary complaint, etc.) or injury (sprain/strain, cut, back injury, etc.)?

\section{For Patients with a Primary Care Provider (PCP)}

- How easy is for you to get an appointment to see your PCP for a minor medical complaint or injury?

- How would you describe your relationship with your PCP?

- What type of routine screening does your PCP do in the office: blood pressure, diabetes screening, screening for cervical/colon/breast cancer, depression screening?

\section{For Patients with no PCP}

- When is the last time you had a PCP? What happened?

- Describe any attempts you have made to establish care with a PCP in this area.

- Do you receive regular screening for high blood pressure, diabetes, cervical/colon/breast cancer, depression? (Stress importance.)

\section{Delayed or Foregone Care - All}

- Can you give an example of any time that you (or someone you know) has had a significant delay in receiving medical care or has gone without care because you either couldn't get in to see your PCP or had no PCP? 
0030-0035

0035-0045

0045-0055

0055-0070

0070-0080

\section{Use of the Emergency Department}

- Have you (or someone you know) ever used the Emergency Department (ED) for a nonurgent problem because you could not be seen elsewhere? Tell us about that experience including cost and time spent in that visit.

\section{Barriers to Care - Patient Level}

- How do your own personal circumstances keep you from being able to see a doctor regularly?

- Can you share any possible solutions to these issues?

\section{Barriers to Care - Provider Level}

- Have you (or someone you know) experienced issues with a provider or clinic that keep you from returning to that clinic or seeking care in a different clinic?

- Can you share any possible solutions to these issues?

- Do you think that we have enough healthcare providers on the coast and what can be done to attract more providers to this area?

\section{Barriers to Care - System Level}

- What changes, if any, do you feel need to made in the "system" in order for people to have access to primary healthcare in this area?

- How do you feel about your ability to get specialist care if needed? How would you feel about telemedicine as a possible solution to the need for specialty consultation?

- Do you have any suggestions for possible extended or weekend hours of clinic operations?

- How do factors associated with your insurance affect your decision to seek healthcare?

- How do factors associated with affordability of medical treatment and/or medications influence you decisions on seeking healthcare?

\section{Conclusion}

- Thank you for participating

- Repeat of confidentiality assurance

- Suggestions for future focus group sessions, if appropriate

- Hand out contact information for Suzanne Hewitt 